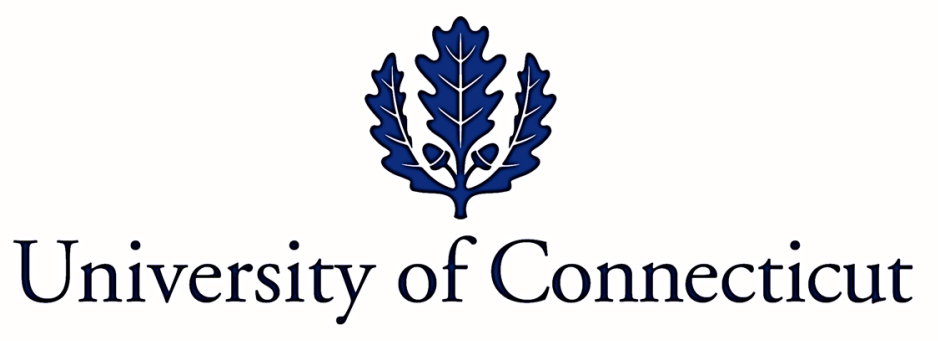

Department of Economics Working Paper Series

Nonparametric Measurement of Potential Gains from Mergers:

An Additive Decomposition and Application to Indian Bank Mergers

by

Subhash C Ray

University of Connecticut

Shilpa Sethia

University of Connecticut

Working Paper 2019-17

September 2019

365 Fairfield Way, Unit 1063

Storrs, CT 06269-1063

Phone: (860) 486-3022

Fax: (860) 486-4463

http://www.econ.uconn.edu/

This working paper is indexed in RePEc, http://repec.org 


\title{
Nonparametric Measurement of Potential Gains from Mergers: An Additive Decomposition and Application to Indian Bank Mergers
}

\author{
Subhash C Ray \\ subhash.ray@uconn.edu \\ Shilpa Sethia \\ shilpa.sethia@uconn.edu \\ University of Connecticut, Storrs CT 06269-1063
}

\begin{abstract}
One of the main incentives for voluntary merger between firms in the same industry is the potential gain in the form of lower cost of producing the combined output of the merging firms. Baumol, Panzar, and Willig (1982) showed that subadditivity of the cost function at the combined output level is a precondition for positive cost gains from a merger. In this paper we build on their theoretical model to derive conditions for potential gains from merger in a short run cost framework where not only the outputs but also the fixed inputs of the merging firms are aggregated through merger. We show that subadditivity of the short run ray total cost curve of the merged firm at the combined output bundle is neither necessary nor sufficient for positive gains from merger. We also provide a decomposition of the potential gain from merger into three components related to convexity of the technology, subadditivity of the short run ray total cost, and decrease in the variable cost due to an aggregation of the fixed inputs. Appropriate linear programming models are formulated for measuring the gain from merger and its components using the nonparametric method of Data Envelopment Analysis. We use data for a number of recent mergers of Indian banks in an empirical application of our proposed models.

Keywords: Sub-additivity, Ray Average Cost, DEA

JEL Classification: L25, D24, G21
\end{abstract}




\section{Nonparametric Measurement of Potential Gains from Mergers: An Additive Decomposition and Application to Indian Bank Mergers}

\section{Introduction}

Horizontal mergers between two or more firms in the same industry are motivated by a variety of factors ranging from overcoming barriers to entry into foreign markets to taking advantage of privileged access to sources of critical inputs. In the theory of Industrial Organization, however, of prime interest is the effect of merger on the cost of production of the combined output bundle of the merging firms. The role of the production technology in determining the optimal configuration of firms in an industry has been analyzed in details by Baumol (1977), Baumol and Fischer (1978), and Baumol, Panzar, and Willig (hereafter BPW) (1982) among others. Baumol and Fischer (1978), in particular, considered the optimal number of firms that could collectively produce the total industry output at the minimum cost. Ray and $\mathrm{Hu}$ (1997) developed a nonparametric optimization model for the technically optimal organization of an industry that would result in the maximum radial scaling down of the aggregate input bundle without reducing the industry output. A different, though closely related, question is whether it is more cost efficient if the outputs of two or more existing firms are combined and produced by a single firm than when produced separately. The cost function is said to be sub-additive at a given output (bundle) if the combined cost of producing any number of smaller output bundles adding up to a specified output bundle is higher than the cost of producing it as a single aggregate bundle. Clearly, there will be incentives for firms to merge voluntarily when the cost function is sub-additive at the combined output bundle. ${ }^{1}$

In the present paper, we circumvent the effect of mergers on market demand by assuming that the target output remains unchanged whether or not the firms merged ${ }^{2}$. This is comparable to Baumol and Fischer (1978), who also assume that the aggregate demand in the market is not affected by the number of firms. However, while Baumol and Fischer (1978) are searching for the optimal number of firms to produce the target output, we are effectively trying to decide between a single firm producing the combined output and the existing distribution of the output between firms being considered for a potential merger.

\footnotetext{
${ }^{1}$ A different type of merger is one where the merging firms are completely specialized in their output choice. Merger, in such cases results in a more diversified firm. Gains from such mergers are known as Economies of Scope. BPW deal in details with scope economies. See, also, Chavas and Kim (2010) and its application in Eder (2018).

2 The post merger output will usually differ from the combined pre-merger outputs of the merging firms due to other factors. We only assume that such changes are not caused by merger itself.
} 
Moreover, our study differs in a fundamental respect from BPW. In examining the question of cost subadditivity, BPW emphasize the role of the startup cost. An important factor behind the possible subadditivity of the cost function is the fact that when produced by a single firm the combined output entails the startup cost only once while the startup cost is incurred by every firm that produces the smaller bundles adding up to the merged output ${ }^{3}$. The implication is that it is an ex ante comparison carried out at the planning stage to decide whether, for producing a target output bundle, a single production unit is more cost efficient than many. By contrast, our evaluation of potential gains from mergers is an ex post analysis in the sense that we consider combining firms, which are already in existence. Thus, each firm considered for merger already has an observed output bundle along with a corresponding observed bundle of fixed inputs. When firms are merged, fixed inputs and, hence the fixed costs, are also combined side by side with the outputs. Another difference is that in our case, change in the fixed costs due to changes in fixed inputs shifts the variable cost function. By contrast, in BPW, variable and marginal costs remain unaffected by startup costs ${ }^{4}$.

While using the basic concepts of sub-additivity and ray convexity of the cost function taken directly from BPW, we focus entirely on the short run ray average cost and total costs specific for the product mix of the merged output bundle and the combined bundle of the fixed inputs. We provide an additive decomposition of the total gain from a merger into three separate components attributable to (i) trans-ray convexity of the technology, (ii) sub-additivity of the short run ray cost curve, and (iii) increase in the bundle of the fixed inputs (broadly described as 'capital expansion'). In this process, we show that subadditivity of the short run ray cost function is neither sufficient nor necessary for gains from merger in the presence of fixed inputs.

Our paper extends the existing literature on mergers and subadditivity of the cost function both conceptually and methodologically. The main contributions of this paper can be summarized as follows:

(i) We adapt the conceptual framework of BPW to a short run analysis and explicitly consider the effect of combining not only the output bundles of the merging firms but their bundles of fixed inputs as well.

\footnotetext{
${ }^{3}$ Even when there is a second dose of a startup/expansion cost beyond a certain level of the output, BPW assume that this second round 'startup' cost is smaller than the initial amount. See their example in (Baumol, Panzar, and Willig (1982) ch 2 page 20).

${ }^{4}$ In the example cited above, their cost function is specified as $C(y)=a+b y$ for $0<y<k$ and $C(y)=a+b y+c$ for $y \geq k$. The change in the fixed/startup cost leaves the variable and the marginal cost unchanged.
} 
(ii) We show that when fixed inputs are present, subadditivity of the ray short run average cost of the merged firm is neither necessary nor sufficient for positive gains in the form of cost reduction due to merger.

(iii) We provide a decomposition of the total gain from merger into three separate components related to (a) convexity of the technology, (b) sub-addtivity of the short run ray total cost of the merged firm, and (c) a tradeoff between fixed and variable costs.

(iv) We formulate appropriate linear programming problems for measuring the potential gains from merger and its different components.

(v) We provide an empirical application of our model using data from several recent mergers of Indian banks.

The rest of the paper is organized as follows. In section 2 we provide the basic microeconomic theory behind sub-additivity and offer the additive decomposition of potential short run gains from merger of a number of firms. Section 3 presents the different nonparametric models of Data Envelopment Analysis (DEA) for empirically measuring the total gain and its components. Section 4 applies the proposed analytical method to a number of actual mergers of Indian banks in recent years. Apart from obtaining point estimates of gains from mergers we also generate statistical distributions of gains from specific mergers through bootstrapping. Section 5 is the summary.

\section{The Theoretical Background}

\section{The Production Technology}

Consider an industry producing $m$ outputs $y \in R_{+}^{m}$ using $n$ inputs $x \in R_{+}^{n}$. Let the production technology of the industry be represented by the closed and bounded production possibility set

$$
T=\left\{(x, y): y \in R_{+}^{m} \text { can be produced from } x \in R_{+}^{n}\right\}
$$

Assume further that

(i) Inputs are freely disposable. That is, if $\left(x^{0}, y^{0}\right) \in T$ and $x^{1} \geq x^{0}$, then $\left(x^{1}, y^{0}\right) \in T$.

(ii) Outputs are freely disposable. That is, if $\left(x^{0}, y^{0}\right) \in T$ and $y^{1} \leq y^{0}$, then $\left(x^{0}, y^{1}\right) \in T$.

(iii) $T$ is convex. That is,

$$
\left(x^{0}, y^{0}\right) \in T \text { and }\left(x^{1}, y^{1}\right) \in T \Rightarrow\left(\lambda x^{0}+(1-\lambda) x^{1}, \lambda y^{0}+(1-\lambda) y^{1}\right) \in T \text { for } 0 \leq \lambda \leq 1 .
$$

The production technology can also be defined in terms of a family of input requirement sets 


$$
V\left(y^{0}\right)=\left\{x: x \text { can produce } y^{0}\right\} \Leftrightarrow\left\{x:\left(x, y^{0}\right) \in T\right\}
$$

Let $\omega \in R_{++}^{n}$ be a strictly positive vector of input prices. Then the minimum cost of producing the output bundle $y^{0}$ is

$$
\begin{aligned}
& C\left(y^{0}, \omega\right)=\min \omega^{\prime} x \\
& \text { s.t. } x \in V\left(y^{0}\right) .
\end{aligned}
$$

Sub-additivity of the cost function: Long run and Short run

Now consider breaking up the bundle $y^{0}$ into $q$ smaller bundles $y^{s}(s=1,2, \ldots, q)$ such that $\sum_{s=1}^{q} y^{s}=y^{0}$. The cost function is sub-additive at $y^{0}$ if for any $q>1$,

$$
\sum_{s=1}^{q} C\left(y^{s}, \omega\right)>C\left(y^{0}, \omega\right) .
$$

As emphasized by BPW, sub-additivity is not a local concept (like scale economies) because one needs information about the cost of all feasible output bundles smaller than $y^{0}$. Clearly, there is a case in favor of merging several firms within the same industry or several units within the same firm if the cost function is sub-additive at the aggregated output bundle. Note that in (3) all inputs are chosen optimally in order to minimize the total cost. Thus, (3) and (4) refer to the long run cost function.

Now suppose that the input vector is partitioned as $x=(v, K)$ where $v$ and $K$ are, respectively, the subvectors of the variable and fixed inputs. Correspondingly, $w$ and $r$ are the price vectors of the variable and the fixed inputs.

Holding $K$ fixed at $K^{0}$ in (2), one can define the conditional input requirement set

$$
V\left(y^{0} \mid K^{0}\right)=\left\{v:\left(v, K^{0}\right) \text { can produce } y^{0}\right\} \Leftrightarrow\left\{v:\left(v, K^{0}, y^{0}\right) \in T\right\}
$$

The minimum cost of producing the output bundle $y^{0}$ at input prices $(w, r)$ with $K$ held fixed at $K^{0}$ is

$$
\begin{aligned}
& C\left(y^{0}, w, r, K^{0}\right)=\min w^{\prime} v+r^{\prime} K^{0} \\
& \text { s.t. } v \in V\left(y^{0} \mid K^{0}\right) .
\end{aligned}
$$


The condition for subadditivity of the short run cost function defined in (6) at $y^{0}$ comparable to (4) above will be

$$
\sum_{s=1}^{q} C\left(y^{s}, w, r, K^{0}\right)>C\left(y^{0}, w, r, K^{0}\right)
$$

There are two complicating factors why (7) does not by itself provide a justification for merger across firms or consolidation within a firm. First, typically the $q$ individual firms under consideration for merger will differ not only in their output bundles $y^{s}$ but also in their bundles of fixed inputs $K^{s}$. Obviously, the short run total cost curves are different when the fixed input bundles are different. Second, when the individual firms are merged, their fixed inputs are also aggregated to $K^{M} \equiv \sum_{s=1}^{q} K^{s}$. Even if the smaller firms had the same bundle of fixed inputs $K^{0}$, the merged firm would have an aggregated bundle of fixed inputs $\left(K^{M} \equiv \sum_{s=1}^{q} K^{s}=q K^{0}\right)$. For positive gains from merger we need

$$
g \equiv \sum_{s=1}^{q} C\left(y^{s}, w, r, K^{s}\right)-C\left(\sum_{s=1}^{q} y^{s}, w, r, \sum_{s=1}^{q} K^{s}\right)>0 .
$$

Clearly, the conditions (7) and (8) are different. In the rest of this section we derive a set of conditions which are together sufficient for positive gains from merger. We also provide an additive decomposition of $g$ into three separate components relating respectively to (a) convexity of the production possibility set (b) subadditivity of the short run cost curve corresponding to the aggregate bundle of fixed inputs $\left(K^{M}=\sum_{s=1}^{q} K^{s}\right)$ at the aggregate output bundle $y^{M}$, and (c) the difference between two short run total cost curves at the average output bundle $\bar{y}$.

For simplicity of exposition, we consider the potential gain (or loss) from merger between two firms $-A$ and $B$. Suppose that their respective output bundles are $y^{A}$ and $y^{B}$ and the fixed input quantities are $K^{A}$ and $K^{B}$. Evaluated at the same input price vector $(w, r)$ the minimum short run costs of producing their outputs given their observed levels of fixed inputs are $C_{A}=C\left(y^{A}, w, r, K^{A}\right)$ and $C_{B}=C\left(y^{B}, w, r, K^{B}\right)$. The cost of producing their combined output $y^{M}=y^{A}+y^{B}$ given the combined bundle of fixed inputs $K^{M}=K^{A}+K^{B}$ is $C_{M}=C\left(y^{M}, w, r, K^{M}\right)$. Thus, the potential gain from merger is 


$$
\begin{aligned}
& g=\left(C^{A}+C^{B}\right)-C^{M} \\
& =\left[C\left(y^{A}, w, r, K^{A}\right)+C\left(y^{B}, w, r, K^{B}\right)\right]-C\left(y^{M}, w, r, K^{M}\right) .
\end{aligned}
$$

Next, define $\bar{y}=\frac{1}{2}\left(y^{A}+y^{B}\right), \bar{K}=\frac{1}{2}\left(K^{A}+K^{B}\right)$, and $\bar{C}=\frac{1}{2}\left(C_{A}+C_{B}\right)$. Thus, the combined output is $y^{M}=2 \bar{y}$ and the combined fixed input is $K^{M}=2 \bar{K}$. Hence, (9) can also be expressed as

$$
g=\left[C\left(y^{A}, w, r, K^{A}\right)+C\left(y^{A}, w, r, K^{A}\right)\right]-C(2 \bar{y}, w, r, 2 \bar{K}) .
$$

Now suppose that the cost minimizing variable input quantities are $\left(v^{A} \mid K^{A}\right)$ for $y^{A}$ and $\left(v^{B} \mid K^{B}\right)$ for $y^{B}$. That is both $\left(v^{A}, K^{A}, y^{A}\right)$ and $\left(v^{B}, K^{B}, y^{B}\right)$ are feasible input-output bundles. Let $\bar{v}=\frac{1}{2}\left(v^{A}+v^{B}\right)$. Therefore, by convexity of the set $T,(\bar{v}, \bar{K}, \bar{y})$ is also a feasible input-output combination. That is $\bar{v} \in V(\bar{y} \mid \bar{K})$. But this need not be the short run cost minimizing bundle of variable inputs. Hence,

$$
w^{\prime}\left(\frac{v^{A}+v^{B}}{2}\right)+r^{\prime}\left(\frac{K^{A}+K^{B}}{2}\right)=\frac{1}{2}\left[C\left(y^{A}, w, r, K^{A}\right)+C\left(y^{B}, w, r, K^{B}\right)\right] \geq C(\bar{y}, w, r, \bar{K}) .
$$

Now, (10) can also be written as

$$
\begin{aligned}
g= & {\left[C\left(y^{A}, w, r, K^{A}\right)+C\left(y^{B}, w, r, K^{B}\right)-2 C(\bar{y}, w, r, \bar{K})\right] } \\
& +2 C(\bar{y}, w, r, \bar{K})-C(2 \bar{y}, w, r, 2 \bar{K}) \\
= & 2\left[\frac{C\left(y^{A}, w, r, K^{A}\right)+C\left(y^{B}, w, r, K^{B}\right)}{2}-C(\bar{y}, w, r, \bar{K})\right]+ \\
& 2\left[C(\bar{y}, w, r, \bar{K})-\frac{C(2 \bar{y}, w, r, 2 \bar{K})}{2}\right] .
\end{aligned}
$$

The expression inside the square brackets in the last term on the right hand side of (12) can be further broken up as

$$
\begin{aligned}
& C(\bar{y}, w, r, \bar{K})-\frac{C(2 \bar{y}, w, r, 2 \bar{K})}{2} \\
& =\left[C(\bar{y}, w, r, 2 \bar{K})-\frac{C(2 \bar{y}, w, r, 2 \bar{K})}{2}\right] \\
& +[C(\bar{y}, w, r, \bar{K})-C(\bar{y}, w, r, 2 \bar{K})]
\end{aligned}
$$

Substituting (13) into (12) one gets 


$$
\begin{aligned}
g & =2\left[\frac{C\left(y^{A}, w, r, K^{A}\right)+C\left(y^{B}, w, r, K^{B}\right)}{2}-C(\bar{y}, w, r, \bar{K})\right] \\
& +2\left[C(\bar{y}, w, r, 2 \bar{K})-\frac{C(2 \bar{y}, w, r, 2 \bar{K})}{2}\right] \\
& +2[C(\bar{y}, w, r, \bar{K})-C(\bar{y}, w, r, 2 \bar{K})]
\end{aligned}
$$

It will be helpful for the empirical application that follows in a later section to separately identify the three terms on the right hand side of (14) as

$$
\begin{aligned}
& I=2\left[\frac{C\left(y^{A}, w, r, K^{A}\right)+C\left(y^{B}, w, r, K^{B}\right)}{2}-C(\bar{y}, w, r, \bar{K})\right] \\
& I I=2\left[C(\bar{y}, w, r, 2 \bar{K})-\frac{C(2 \bar{y}, w, r, 2 \bar{K})}{2}\right] \\
& I I I=2[C(\bar{y}, w, r, \bar{K})-C(\bar{y}, w, r, 2 \bar{K})]
\end{aligned}
$$

At this point a slight digression on scale economies is worthwhile. Consider, first, the single output case. Positive scale economies hold locally if a small percentage increase in the output level results in a smaller percentage increase in the total cost. In this case, the elasticity of cost with respect to output is less than 1. That is $\varepsilon_{C y}=\frac{\partial \ln C}{\partial \ln y}<1$. But that implies that the marginal cost is less than the average cost and the average cost curve is falling at that output level. In the multiple output case, of course, there is no natural interpretation of an average cost. One may, however, consider the ray average cost $R A C=\frac{C\left(t y^{0}, \omega\right)}{t}$. At a given output bundle $y^{0}, t$ equals unity so that the RAC and the total cost are the same at the unit scale. Now suppose that each output in the $y^{0}$ bundle is scaled up by a factor $t>1$. If , as a result, the cost increases by a factor less than $t$, the scale elasticity of cost is less than 1.But also note that in this case, $C\left(t y^{0}, \omega\right)<t C\left(y^{0}, \omega\right)$. That is, $\frac{C\left(t y^{0}, \omega\right)}{t}<C\left(y^{0}, \omega\right)$. This implies that the ray average cost is falling as the scale of the output bundle is increased (without changing the output mix).

Now suppose that some of the inputs are fixed and we are looking at the short run cost function. This time, as the output increases the fixed cost is spread over a larger number of units and continues to fall indefinitely. However, with some inputs held fixed the variable cost will eventually increase more than proportionately as the output increases. At that stage, increase in the average variable cost will more than 
offset the decline in the average fixed cost so that the short run average cost increases. Hence, it is reasonable to assume the $U$ shape of the average cost curve in the short run (whether or not it is $U$ shaped in the long run $)^{5}$. This argument applies just as well to the ray average cost in the multiple output case. That is, economies of scale holds locally if an output bundle $t y^{0}$ is located on the declining segment of the short run ray average cost curve for a given bundle of the fixed inputs, $\frac{C\left(t y^{0}, w, r \mid K^{0}\right)}{t}$. But, as is shown below, even if it is located on the upward rising segment so that locally diseconomies of scale holds at $t y^{0}$, the short run cost function may still be sub-additive at that output scale $t$.

We now return to equation (14) and explain each of the three terms on the right hand side geometrically in Figures 1-3. For simplicity we consider the two-output case. The outputs are measured along the two axes labeled $y_{1}$ and $y_{2}$ and the third axis measures cost. The points $y^{A}$ and $y^{B}$ show the output bundles of the firms $A$ and $B$. The rays through $y^{A}$ and $y^{B}$ in the output space show radial expansion/contraction of the output bundles of $A$ and $B$. The curves $C\left(t y^{A} \mid K^{A}\right)$ and $C\left(t y^{B} \mid K^{B}\right)$ are two short run ray total cost curves for fixed input bundles $K^{A}$ and $K^{B}$, respectively. The corresponding fixed costs, $F C_{y_{A}}$ and $F C_{y_{B}}$, are shown by the two vertical intercepts. Similarly, the point $\bar{y}$ is the average output bundle and $C(t \bar{y} \mid \bar{K})$ is the short run ray total cost curve for the fixed input bundle $\bar{K}$ and $F C_{\bar{y}}$ is the associated fixed cost. The points $P, Q$, and $R$ show $C\left(y^{A} \mid K^{A}\right), C\left(y^{B} \mid K^{B}\right)$, and $C(\bar{y} \mid \bar{K})$. The point $S$ is the mid-point of the line segment $P Q$ and is the average of $C\left(y^{A} \mid K^{A}\right)$ and $C\left(y^{B} \mid K^{B}\right)$. Convexity of the production possibility set ensures that the point $S$ lies above $R$. The first term on the right in (14) is twice the amount $S R$.

In Figure 2, we consider the question of subadditivity of the short run ray cost function $C(t \bar{y} \mid 2 \bar{K})$ at $t=2$. Note that because we consider an unchanged output mix, we can measure the change in the scale along the horizontal axis and the corresponding short run total cost up the vertical axis so that the usual 2dimensional diagram is adequate. The points $P$ and $Q$ on the same ray total cost curve show the short run total cost of the bundles $\bar{y}$ (i.e., at $t=1$ ) and $y^{M}=y^{A}+y^{B}=2 \bar{y}$ (i.e. $t=2$ ). At $\bar{y}, \mathrm{t}=1$ and the total and

${ }^{5}$ Consider the 1-output 2-input production function $y=2 \sqrt{K L}$. With the input prices $\mathrm{r}$ and $\mathrm{w}$ for $\mathrm{K}$ and $\mathrm{L}$, respectively, the long run cost function is $C=\sqrt{w r} y$ and the average cost is $\frac{C(y, w, r)}{y}=\sqrt{w r}$ which is horizontal. But if $\mathrm{K}$ is held fixed at $\mathrm{K}_{0}$, the short run cost curve is $C\left(y, w, r \mid K_{0}\right)=r K_{0}+\frac{w}{4 K_{0}^{2}} y^{2}$ and the short run average cost is $\frac{C\left(y, w, r \mid K_{0}\right)}{y}=\frac{r K_{0}}{y}+\frac{w}{4 K_{0}^{2}} y$, which can be easily verified to be $\mathrm{U}$ shaped. 
ray average cost are both equal to the slope of the line $O P$. By comparison, the ray average cost at $y^{M}=2 \bar{y}$ is measured by the slope of $O Q$. Two other points of interest in this diagram are $R$ and $S$. At $R$, where the ray average cost reaches a minimum, $t=t^{*}$. This is the output scale which can be described as the cost efficient production scale in the short run. Scale economies are present at all production scales up to $t^{*}$, where scale economies have been exhausted. Beyond that, diseconomies of scale are present. That is, ray average cost is rising at points to the right of $R$. Thus, in this example, diseconomies of scale are present at $y^{M}=y^{A}+y^{N}=2 \bar{y}$. Nevertheless, so long at the point $Q$ lies to the left of $S$, the other point of interest in Figure 2, ray average cost will be lower at $Q$ than at $P$. At $S$ the ray average cost has caught up to what it was at $P$. This is evident from the fact that the points $\mathrm{P}$ and $\mathrm{S}$ both lie on the same ray through the origin in Figure 2. We identify the scale at $S$ as $t^{\max }$. For $t^{*}<2<t^{\max }$ subadditivity holds without economies of scale. Of course, if $t^{*} \geq 2$, economies of scale exist at $y^{M}$ and along this short run ray total cost curve, subadditivity holds at $y^{M}$.

This discussion, of course, assumes that we are considering the merger of two units. In other words, we are comparing the cost of production of $y^{M}$ with the total cost of producing $y^{M}$ broken up into any two smaller bundles. What happens if $y^{M}$ was broken up into $q$ bundles $(q>2)$ ? Two changes need to be considered. First, for $\mathrm{q}>2$, for the same aggregate bundle $y^{M}, \bar{y}=\frac{y^{M}}{q}$ will be a smaller bundle. Also, when a different set of firms are merged, the aggregated bundle of fixed inputs $K^{M}=\sum_{s=1}^{q} K^{s}$ will usually be different from $K^{A}+K^{B}$ so that the short run ray total cost curve also will be different. However, so long as $\quad q \leq t^{\max }$, ray average cost at $y^{M}=q \bar{y}$ is lower than the cost of the bundle $\bar{y}$. That is, the ray short run cost curve for $K^{M}$ is sub-additive at $y^{M}$.

Finally, Figure 3 shows the tradeoff between the reduction in the variable cost and the increase in the fixed cost as the fixed input bundle is increased from $\bar{K}$ to $K^{M}=2 \bar{K}$. The two short run ray total cost curves for $t \bar{y}$ are labeled $C(t \bar{y} \mid \bar{K})$ and $C(t \bar{y} \mid 2 \bar{K})$. At $t=1$, i.e., $(t \bar{y}=\bar{y}), C(\bar{y} \mid \bar{K})=R \bar{y}$ and $C(\bar{y} \mid 2 \bar{K})=S \bar{y}$ so that there is a net reduction of cost by $R S$. The increase in the fixed cost is $2 r \bar{K}-r \bar{K}=P Q$ whereas the decline in variable cost is $P R-Q S$. The net result is the reduction in short run total cost by $R S$. In any specific case, whether the net change in cost will be positive (i.e., increase) or 
negative (i.e., decrease) will depend on whether the $\bar{y}$ bundle is located to the left or to the right of the point $T$ where the two curves intersect.

\section{The Nonparametric Models}

In this section we present the different optimization models using the nonparametric method of DEA to evaluate the various short run ray total and average cost curves needed to measure the potential gains from merger of firms and also to additively decompose the total gain into the three components shown in equation (14) above.

Assume that we have the data on input and output bundles along with the input prices for $N$ firms in an industry. Suppose that $y^{j}(j=1,2, . ., N)$ is the observed output bundle and $x^{j}(j=1,2, \ldots, N)$ is the corresponding input bundle observed for firm $j$. Further, suppose that each input vector can be partitioned as $x^{j}=\left(v^{j}, K^{j}\right)$ where $v$ and $K$ are the sub-vectors of variable and fixed inputs. Under the assumption of free disposability of outputs and inputs along with convexity of the technology, one can empirically approximate the production possibility set as

$$
\widehat{T}=\left\{\begin{array}{l}
(v, K, y): v \geq \sum_{j=1}^{N} \lambda_{j} v^{j} ; K \geq \sum_{j=1}^{N} \lambda_{j} K^{j} \\
y \leq \sum_{j=1}^{N} \lambda_{j} y^{j} ; \sum_{j=1}^{N} \lambda_{j}=1 ; \lambda_{j} \geq 0 ;(j=1,2, \ldots, N)
\end{array}\right\}
$$

\section{Finding the Multi-output Short run Total Cost}

For any output bundle $y^{0}$ the short run total cost at any given input price vector $\omega=(w, r)$ for the fixed input bundle $K^{0}$ can be obtained as 


$$
\begin{gathered}
C\left(y^{0}, w, r \mid K^{0}\right)=\min w^{\prime} v+r K^{0} \\
\text { s.t. } \sum_{j=1}^{N} \lambda_{j} y^{j} \geq y^{0} ; \\
\sum_{j=1}^{N} \lambda_{j} v^{j} \leq v ; \\
\sum_{j=1}^{N} \lambda_{j} K^{j} \leq K^{0} ; \\
\sum_{j=1}^{N} \lambda_{j}=1 ; \lambda_{j} \geq 0 ;(j=1,2, \ldots, N)
\end{gathered}
$$

Using $\left(y^{A}, K^{A}\right),\left(y^{B}, K^{B}\right)$, and $\left(y^{M}, K^{M}\right)=\left(y^{A}+y^{B}, K^{A}+K^{B}\right)$ for $\left(y^{0}, K^{0}\right)$ in (16) we can get $C\left(y^{M}, w, r \mid K^{M}\right), C\left(y^{A}, w, r \mid K^{A}\right)$, and $C\left(y^{B}, w, r \mid K^{B}\right)$ from which one can measure the potential gain from merger of the units $A$ and $B$ defined above in (9).

The other costs, $C(2 \bar{y}, w, r ; 2 \bar{K}), C(\bar{y}, w, r, 2 \bar{K})$, and $C(\bar{y}, w, r, \bar{K})$ can also be similarly obtained from (16) using $\bar{y}=\frac{y^{A}+y^{B}}{2}, \bar{K}=\frac{K^{A}+K^{B}}{2}$, and $2 \bar{K}=K^{A}+K^{B}$ for parameters in (16), as appropriate.

\section{Finding the Short run Cost efficient Production Scale:}

The cost efficient production scale of any output bundle $y^{0}$ is $t=t^{*}$ where the short run ray average cost for a bundle of fixed inputs $K^{0}, R A C\left(t y^{0}, w, r \mid K^{0}\right)=\frac{w^{\prime} v+r K^{0}}{t}$ is minimized subject to the condition that $\left(v, K^{0}, y^{0}\right) \in T$. Under variable returns to scale, the relevant DEA optimization problem is

$$
\begin{aligned}
& \min \frac{w^{\prime} v+r^{\prime} K^{0}}{t} \\
& \text { s.t. } \sum_{j=1}^{N} \lambda_{j} y^{j} \geq t y^{0} ; \\
& \sum_{j=1}^{N} \lambda_{j} v^{j} \leq v ; \\
& \sum_{j=1}^{N} \lambda_{j} K^{j} \leq K^{0} ; \\
& \sum_{j=1}^{N} \lambda_{j}=1 ; \lambda_{j} \geq 0 ;(j=1,2, \ldots, N)
\end{aligned}
$$


This, clearly, is a non-linear programming problem. However, following Ray, Walden, and Chen (2018), one can define the variables

$$
\mu_{j}=\frac{1}{t} \lambda_{j}, u_{j}=\frac{1}{t} v_{j}, \text { and } z^{0}=\frac{1}{t} K^{0}
$$

Then,

$$
\sum_{j=1}^{N} \mu_{j}=\frac{\sum_{j=1}^{N} \lambda_{j}}{t}=\frac{1}{t} \Rightarrow t=\frac{1}{\sum_{j=1}^{N} \mu_{j}} .
$$

It may be noted that although the $K^{0}$ is a parameter vector, $z^{0}=\frac{1}{t} K^{0}$ is a vector of choice variables because $t$ is a choice variable. The non-linear problem can be written as the following linear programming problem:

$$
\begin{aligned}
& \min w^{\prime} u+r^{\prime} z^{0} \\
& \text { s.t. } \sum_{j=1}^{N} \mu_{j} y^{j} \geq y^{0} \\
& \sum_{j=1}^{N} \mu_{j} v^{j} \leq u \\
& \sum_{j=1}^{N} \mu_{j} K^{j} \leq z^{0} \\
& z^{0}=\sigma K^{0} ; \\
& \sum_{j=1}^{N} \mu_{j}=\sigma ; \mu_{j} \geq 0 ;(j=1,2, \ldots, N)
\end{aligned}
$$

From the optimal choice of the LP problem in (20), we can get the cost efficient scale as $t^{*}=\frac{1}{\sigma^{*} \text {. }}$.

Finding the Maximum Scale for Subadditivity

An interesting question is whether for a specific output bundle $y^{0}$, all larger bundles with the same output mix have a higher ray average cost. This seemingly unrelated question can have serious implications about the subadditivity of the short run ray total cost function at the merged output bundle. We have seen that if the average output bundle of the units being merged is bigger than its cost efficient short run production scale, then the merged output bundle cannot have a lower ray average cost. But, even 
if it is smaller than the optimal scale, $t^{*}$, that by itself does not guarantee a lower ray average cost at the merged bundle $y^{M}$ unless $t^{\max }$ is greater than the number of units being merged. The critical points are

$$
C\left(y^{0}, w, r \mid K^{0}\right)=\frac{C\left(t^{\max } y^{0}, w, r \mid K^{0}\right)}{t^{\max }},
$$

And

$$
\frac{C\left(\mathrm{t} y^{0}, w, r \mid K^{0}\right)}{t} \leq C\left(y^{0}, w, r \mid K^{0}\right) \text { for } 1 \leq t \leq t^{\max } .
$$

In order to determine $t^{\max }$ for any output bundle $y^{0}$ for the short run cost function corresponding to $K^{0}$ we first solve the LP problem is (16) to determine $C\left(y^{0}, w, r \mid K^{0}\right)=C^{*}\left(y \mid K^{0}\right)$.

Next we solve the problem

$$
\begin{aligned}
& t^{\max }=\max t \\
& \text { s.t. } \sum_{j=1}^{N} \lambda_{j} y^{j} \geq t y^{0} ; \\
& \sum_{j=1}^{N} \lambda_{j} v^{j} \leq v ; \\
& \sum_{j=1}^{N} \lambda_{j} K^{j} \leq K^{0} ; \\
& t C^{*}\left(y^{0} \mid K^{0}\right)-w^{\prime} v=r K^{0} ; \\
& \sum_{j=1}^{N} \lambda_{j}=1 ; \lambda_{j} \geq 0 ;(j=1,2, \ldots, N)
\end{aligned}
$$

\section{Empirical Application: Analysis of Selected Mergers from Indian Banking}

In this section we use data from Indian banking for empirical illustration of the methodology proposed above. We analyze potential gains from actual mergers of domestic banks in India over the period 20002019. These past two decades have witnessed a large number of mergers and acquisitions in most banking systems around the world. This has prompted research on the effectiveness of such reorganizations on performance of the banks involved and has produced mixed results (e.g., DeYoung et al. (2009)). A significant number of studies have evaluated mergers within the U.S. banking, like Berger and Humphrey (1992, 1997), Peristiani (1997), Rhoades (1998), Houston et al. (2001), Berger and Mester (2003), AlSharkas et al. (2008), Knapp et al. (2005) and Lin (2010) to name a few. Several empirical studies have 
examined bank mergers in Europe, both at pan-Europe level and for various individual European countries- Resti and Siciliano (2001), Campa and Hernando (2006), Altunbas and Ibanez (2008), Valverde and Humphrey (2004), Humphrey and Vale (2004), De Guevara et al. (2005), De Guevara and Maudos (2007). More recent research has also focused on mergers in developing and transition economies and some well-developed Asian countries; Fadzlan (2004) examined technical and scale efficiency changes among the Malaysian banks following a merger and noted efficiency gains due to the benefits of economies of scale for the small and medium sized banks. Lien-Wen (2011) measured cost efficiency of the Japanese and Taiwanese banks and observed merger-induced cost-savings but only for the Japanese banks. Hosono et al. (2006) also confirmed improved post-merger cost and profit efficiency for Japanese banks. Research using Indian banks data typically follow Rhoades (1998) and considers a three-years period preceding and succeeding a merger over which the performance of acquiring banks is evaluated - Gourlay et al. (2006), Kaur and Kaur (2010), Kollapuri (2017). ${ }^{6}$

In the literature on mergers, there are three prevalent means of assessing merger-induced financial gains: ratio analysis (Berger and Humphrey (1992), Rhoades (1998), Mylonidis and Kenikola (2005), Sufian et al. (2008), Naga and Tabassum (2013), Kumar (2013), Mondal et al. (2017), etc.), event study analysis, measuring stock market responses to the announcements or conclusion of merger deals (Houston and Ryngaert (1994), Pilloff (1996), DeLong (2001), Cornett et al. (2003), DeLong and DeYoung (2007), Sensarma and Jayadev (2010), Patel and Shah (2016), Kiesel, Ries, and Tielmann (2017)), and frontier analysis for efficiency evaluation of mergers using SFA, DEA and/or both (Peristiani (1997), Fried, Lovell, and Yaisawarng (1999), Al-Sharkas et al. (2008), Singh (2009), Berger and Mester (2003)).

A limited number of recent studies have taken an alternative approach and concentrated on ex-ante estimates of viability of hypothetical mergers. Emmons et al. (2004) considered hypothetical mergers among the U.S. commercial banks to measure potential benefits accruing from increased size and geographical footprint. Lin et al. (2008) developed a simulation model to determine candidates for a merger that improves riskiness and efficiency of banks in Taiwan. Lozano (2013) proposed a DEA model to choose the best partner for a joint venture. Other studies evaluating returns from hypothetical reorganization of activities include Gattoufi et al. (2014) and Blancard et al. (2016). By far the most popular approach for assessing potential gains from a merger is the production model of Bogetoft and Wang (2005), henceforth BW. They provide a multiplicative decomposition of the overall gains from a merger and ascribe it to three different components, arising due to improved efficiency, a change in the

\footnotetext{
${ }^{6}$ According to Rhoades (1998), experts in the banking industry believe that half of the efficiency gain from any merger becomes evident within a year of merger and all gains are realized within three years of the merger.
} 
scale of operation, and a change in the output mix (which they call the harmony effect). They apply the model to estimate gains from merging agricultural extension offices in Denmark. Mattsson and Tidana (2019) applied the output oriented version of the BW model to evaluate potential efficiency gains from merging the district courts of Sweden. Shi et al. (2017) in their study of Chinese banks also focus on the three efficiency measures of BW; the only difference being, they construct their frontier including the hypothetical merged banks. Gourlay et al. (2006) followed output-oriented BW approach to evaluate potential gains from the Indian bank mergers and compared it with the post-merger output efficiency of the acquiring bank. Aside from this, studies concerning prospective evaluation of merger gains in the Indian context are practically absent. Our study adds to the extant literature by retrospectively evaluating the probable cost effects of some actual Indian bank mergers (measured one year prior to the merger year). Three sources of cost-savings are identified from our theoretical model: gains from offering a different product-mix (gains from convexity), from sub/super-additivity of the ray short run total cost function of the combined output, and from increased availability of fixed inputs (gains from capital expansion). ${ }^{7}$ Over the last two decades, there were 21 actual mergers between domestic commercial banks in India, of which we consider $13 .{ }^{8}$ As listed in Table 1 all but 4 out of these 13 were forced mergers dictated by the central bank of the country, Reserve Bank of India (RBI), to avoid the threat of insolvency of at least one of the constituent banks. The remaining 4 were voluntary mergers motivated by the prospect of economic gains.

It is generally agreed that as a commercial firm a bank is best treated as a financial intermediary between lenders and borrowers. In this paper also we take the intermediation approach and (along the lines of Sealy and Lindley (1977), Berger and Mester (1997) and others) treat deposits $\left(x_{1}\right)$, labor $\left(x_{2}\right)$, and physical capital (fixed assets) $\left(x_{3}\right)$ as inputs while performing loans and advances $\left(y_{1}\right)$, investments $\left(y_{2}\right)$, and other (non-interest) income $\left(y_{3}\right)$ as outputs). ${ }^{9}$ Further, as in Ray and Das (2010), we treat capital and reserves or equity $(e)$ as a fixed input. Price of deposits $\left(w_{1}\right)$ is measured by interest expense per rupee of deposits. The price of labor $\left(w_{2}\right)$ computed by the ratio of total salaries paid salaries to the number of employees. The user cost of fixed assets $\left(w_{3}\right)$ is obtained by dividing the sum of depreciation, rent, and

\footnotetext{
${ }^{7}$ Gains from convexity is referred to as "Harmony Effect" in BW.

${ }^{8}$ Out of the total 8 mergers excluded from our analysis, 5 are left out because data on at least one of the constituent banks involved in these mergers were unavailable: HDFC Bank and Times Bank (2000), ICICI Bank and ICICI Limited (2002), Bank of Baroda and South Gujarat Local Area Bank (2004), IDBI Limited and IDBI Bank (2005) and ICICI Bank and Sangli Bank (2007). The remaining 3 involved mergers within the State Bank group, with the State Bank of India (SBI) being the acquirer bank. SBI is the largest public sector bank in the country, alone accounting for close to $40 \%$ share in all the business parameters of the Indian banking. These mergers within the State Bank group were not motivated by cost considerations and are therefore, not particularly meaningful in the present context.

${ }^{9}$ Performing loans are measured as the difference between total loans and nonperforming loans.
} 
amortization by the book value of gross fixed assets. Finally, the price of equity $\left(w_{e}\right)$ is measured by the rate of interest earned on loans and investments. Data on inputs and outputs of all domestic commercial banks in India are obtained from the statistical publications of the RBI. ${ }^{10}$

Table 2 presents the summary statistics of the variables for selected years and the reported numbers are adjusted for inflation. The increased pace of consolidation in the Indian banking sector led to a decline in the number of public sector banks from 27 in 2000 and in 2010 to 21 in 2018 . The number of private sector banks declined from 32 in 2000 to 22 in 2010 due to merger of some old private sector banks. Despite a decrease in the number, the average asset holding of banks is much bigger than what it was a decade ago. Similar trend is also obvious from the statistics based on the average size of bank deposits and advances. Macroeconomic growth of the economy coupled with the reorganization of industry via mergers and amalgamations enabled the Indian commercial banks, specially the public sector banks, in achieving greater financial deepening.

In the non-parametric literature on production, the efficiency of a merger between firms in an industry is typically evaluated by comparing the efficiency levels of the acquiring firm for several periods before and after the merger. In this, the technical or cost efficiency of the other firm(s) involved in the merger plays no role whatsoever. In the analytical method proposed above, we incorporate the pre-merger performance of all the merging banks in the evaluation of merger gains. We use the input-output data from the year preceding a merger for banks that merged in the subsequent year to examine whether a merger in the year analyzed would have resulted in a lower cost. In performing the cost analysis we use the input prices paid by the acquiring bank instead of the actual prices paid by the individual banks. We emphasize that the mix of the combined output of the merging banks during the year prior to the merger is different from the output mix of the merged bank after the merger. ${ }^{11}$ Hence, the estimated potential gain/loss from the hypothetical merger in the preceding year need not be realized in the year following the actual merger.

Table 3 provides the measure of potential cost gains from the mergers reported in Table 1 along with the decomposition of the total percentage gain into the three components representing convexity, subadditivity of the short run ray cost function, and 'capital expansion' due to merger. Out of the 13 mergers

\footnotetext{
${ }^{10} \mathrm{We}$ omit foreign banks from our analysis. Foreign banks have sufficiently large amount of capital resources, superior technology, considerable international exposure, well established network and they operate exclusively in urban and metropolitan areas (Kumar and Gulati (2014)). Consequently, foreign banks tend to have a very different functionality and organizational structure than their domestic counterparts even though they all operate under the broad guidelines of the RBI.

${ }^{11}$ Yuan et al. (2020) explain that yield uncertainty has favorable implications on the post-merger performance/profitability of acquiring firms. They show that firms have an incentive to merge in presence of high yield uncertainty even without any evidence of substantial potential reduction in the marginal cost of production.
} 
reported 8 showed potential cost reduction (i.e., positive gains) while the remaining 5 showed cost increase. Interestingly, out of the 5 cases showing potential loss 4 were forced mergers: (i) M1 between Bank of Baroda, Dena Bank, and Vijaya Bank, (ii) M3 between ICICI Bank and Bank of Rajasthan, (iii) M7 between IDBI and United Western Bank, and (iv) M11 between Punjab National Bank and Nedungadi Bank. By contrast, the only voluntary merger showing potential loss was M11 between ICICI Bank and bank of Madura. Merger between Centurion Bank and Bank of Punjab (M9) showed the highest potential gain (16.77\%) while the maximum potential loss (21.6\%) was found for M7, the merger between IDBI Bank and United Western Bank.

For a clear understanding of the different components of the potential gain/loss reported for the individual mergers in Table 3, we consider in Table 4, the details of M9 (merger between Centurion Bank and Bank of Punjab). The actual merger took place in 2005. To measure the potential gain we considered the output quantities and input quantities and prices for the year 2004 - the last year before the merger. Also, we used the prices of Centurion bank to evaluate the efficient short run costs for the individual banks along with that of the hypothetically merged bank in 2004 (the last pre-merger year). Table 4 provides the basic information for measuring the percentage gain from this hypothetical merger of the two banks in 2004 . The first two rows show the amounts of outputs and the fixed input (equity) (in ₹ millions). The optimal cost column shows the minimum short run cost of producing the output bundles of the two banks at the prices paid by Centurion Bank (the acquiring bank) in 2004. The boldface row "Total" shows the sum of the standalone costs of the two banks. The row labeled 'Average' shows the average output bundle and the average amount of equity of the two banks, and the corresponding minimum short run cost of producing the average output bundle. The last row shows the short run cost of producing the combined output bundle by the hypothetical merged bank using the combined equity as the fixed input. The difference between the total costs from two standalone bundles by the two banks (with their existing equities) and the cost of producing the combined bundle by a single merged bank is the potential gain of $₹ 628 \mathrm{~m}$, which is $16.77 \%$ of the total (as shown in the relevant row of Table 4).

We may now look at the three components of this gain from the merger. The average of the costs of the two standalone bundles is ₹ $1,872 \mathrm{~m}$ while the cost of the average of the two bundles is ₹ $1,696 \mathrm{~m}$. Their difference is ₹176m, which corresponds to the line segment $R S$ in Figure 1. Hence, the gain due to convexity as shown in (14a) above is ₹352m.

For the sub-additivity component we focus on the short run ray total cost curve for the aggregate equity level, $C\left(t \bar{y}, w, r \mid K^{M}\right)$. For the average output bundle, $C(\bar{y}, w, r \mid 2 \bar{K})$ is $₹ 1,731 \mathrm{~m}$ and for the aggregate output bundle, $C(2 \bar{y}, w, r \mid 2 \bar{K})$ is ₹3,116m. Thus, the ray average cost at the aggregate bundle $2 \bar{y}$ is 
$₹ 1,558 \mathrm{~m}$. Because the average output bundle is itself regarded as one unit of the composite output, the decline in the ray average cost is the difference $₹ 173 \mathrm{~m}$. This corresponds to the difference $P U$ at $t=1$ in Figure 2. As defined in (14b) the contribution of sub-additivity of the ray average cost is a gain of ₹346m.

Finally, we look at the short run total cost curves for the average equity level and the aggregate equity level. For the average output bundle, the costs are $C(\bar{y}, w, r \mid \bar{K})=₹ 1,696 \mathrm{~m}$ and $C(\bar{y}, w, r \mid 2 \bar{K})=$ $₹ 1,731 \mathrm{~m}$. In this case, increase in the fixed cost is not fully offset by decline in the variable cost and the cost of the average bundle would increase by ₹35m. Unlike what is shown in Figure 3, in this case the point $S$ would lie above the point $R$. Corresponding to (14c), the capital expansion effect is a loss of $₹ 70 \mathrm{~m}$. The potential gain/loss from the other mergers reported in Table 3 and the corresponding break down by components were similarly computed.

The values of $t^{*}$ (the optimal scale) and $t^{\max }$ (the maximum scale) provide interesting information about scale economies and sub-additivity of the short run ray average cost curve for the output-mix and the combined amount of equity of the merged bank. Consider, for example the merger M3 (between ICICI Bank and Bank of Rajasthan). The value of $t^{*}$ equal to 1.89 implies that the minimum of the ray short run average cost is attained at the output bundle $1.89 \bar{y}$ and the combined output of the two banks is $y^{M}=2 \bar{y}$ falls in the region of diseconomies of scale. However, because $2<t^{\max }=2.21$, the ray average cost at $y^{M}=2 \bar{y}$ is still lower than what it is at $\bar{y}$. On the other hand, for M9 (merger between Centurion Bank and Bank of Punjab, considered in table 4) and M2 (between Kotak Mahindra Bank and ING Vysya Bank) $t^{*}$ is greater than 2 (2.03 for M2 and 2.02 for M9). Thus, in both cases, the output bundle of merged bank falls in the region of positive economies of scale. Consequently, the sub-additivity component in the corresponding row is positive. Contrast this with M13 (merger between ICICI Bank and Bank of Madura). In this case $t^{*}$ is 1.26 and $t^{\max }$ is 1.60 . Hence $y^{M}=2 \bar{y}$ falls not only in the region of diseconomies of scale but also in the region where the ray average cost his higher than that at $\bar{y}$. Hence, the sub-additivity component is negative. Finally, for M11 (merger between Punjab National bank and Nedungadi Bank) $t^{*}$ is 0.86 and $t^{\max }$ is 1 . This means that the average bundle $\bar{y}$ itself is in larger than the optimal scale and falls in the region of diseconomies of scale. Further, because $t^{\max }$ is 1 , any increase in the scale would lead to a higher ray average cost. That is what happens at $y^{M}=2 \bar{y}$ and the sub-additivity component in the row for M11 is negative. 


\section{Bootstrap Analysis}

One well known criticism of the nonparametric DEA model is that it does not accommodate random variations in the data and any deviation from the frontier constructed from a realized sample is interpreted as inefficiency. The popular response is to generate multiple pseudo data sets through bootstrapping and to approximate the frontier repeatedly using the bootstrap samples. Following Simar and Wilson (1998) analysts typically generate numerous values of the maximum radial expansion factor of an observed output bundle produced from a given input bundle through kernel-smoothed bootstrapping. Ray (2015) created bootstrap samples for the single output multiple input case but subsequently used the samples to generate an empirical distribution of the minimum cost of producing a specified output quantity by repeatedly solving the cost minimization problem for each bootstrap sample. One problem in the present case is that we have multiple outputs and bootstrapping the radial expansion factor would not take into account possible output slacks. We circumvent this problem by using a non-radial output-oriented DEA model. For our 3-output case, we use the observed data set to get triplets of the non-radial expansion factors by solving the DEA model

$$
\begin{aligned}
& \max \frac{1}{3} \sum_{r=1}^{3} \varphi_{r} \\
& \text { s.t. } \\
& \sum_{j=1}^{N} \lambda_{j} y_{r j} \geq \varphi_{r} y_{r 0}(r=1,2,3) \\
& \sum_{j=1}^{N} \lambda_{j} x_{i j} \leq x_{i 0}(i=1,2,3) \\
& \sum_{j=1}^{N} \lambda_{j} K_{j} \leq K_{0} ; \\
& \sum_{j=1}^{N} \lambda_{j}=1 ; \varphi_{r} \geq 1 ; \lambda_{j} \geq 0(j=1,2, \ldots, N)
\end{aligned}
$$

Once we get the triplets $\varphi_{j}^{*}=\left(\varphi_{1 j}^{*}, \varphi_{2 j}^{*}, \varphi_{3 j}^{*}\right)(j=1,2, . ., N)$ we draw $\mathrm{N}$ triplets from the optimal solutions by random sampling with replacement. Let $\tilde{\varphi}_{j}^{*}=\left(\tilde{\varphi}_{1 j}^{*}, \tilde{\varphi}_{2 j}^{*}, \tilde{\varphi}_{3 j}^{*}\right)(j=1,2, . ., N)$ be one such bootstrap sample. We then apply the standard procedure for Gaussian kernel smoothing to get the smoothed bootstrap values $\tilde{\varphi}_{j}^{s}=\left(\tilde{\varphi}_{1 j}^{s}, \tilde{\varphi}_{2 j}^{s}, \tilde{\varphi}_{3 j}^{s}\right)(j=1,2, . ., N)$. The smoothed bootstrap output data form the jth observation is then created as $\tilde{y}_{r j}^{s}=\frac{\varphi_{r j}^{*}}{\tilde{\varphi}_{r j}^{s}} y_{r j}(r=1,2,3)$. The free disposal convex hull of the bootstrap output bundles coupled with the actual input bundles is used to approximate VRS production possibility 
set $\tilde{T}^{s}$ for each bootstrap replication. The minimum short run total costs of the actual individual output bundles and the combined bundle are computed for each such technology set and the gain/loss from merger is computed. Table 5 reports the 5-, 50-, and 95-percentile of the bias-corrected empirical distribution function of the gain from each of the 13 mergers considered above based on 1,000 smoothed bootstrap samples. One clarification is in order at this point. The input-output data from the actual sample are not included in the construction of the bootstrap frontiers. As a result, in a number of cases, the observed input-output bundles (and especially, the merged output bundle) fell outside the constructed frontier and the corresponding DEA problem for cost minimization under VRS was infeasible. As mentioned in the footnote below Table 5, this happened in 642 cases for M1 (between Bank of Baroda, Dena Bank, and Vijaya Bank), 81 times for M3 (between ICICI Bank and Bank of Rajasthan), 275 times for M4 (between HDFC Bank, Centurion Bank, and Lord Krishna Bank), and 192 times for M11 (between Punjub National Bank and Nedungudi Bank).For these 4 mergers the reported percentiles are for the feasible cases only.

It is interesting to note that both the point estimates of gain/loss from the actual data and the corresponding value of the bootstrap median (50-percentile) have the same sign in 11 out of the 13 cases considered. The two disagreements were in the case of M3 (between ICICI Bank and Bank of Rajasthan) where the point estimate was a loss but the median indicated a gain and M10 (between Oriental Bank of Commerce and Global Trust Bank) where the actual data showed a gain but the median indicated a loss. Moreover, in those cases where their signs matched, the point and the median estimates of the gains/loss were generally quite close (within 2 percentage points) except for M4 (between HDFC Bank, Centurion Bank of Punjab, and Lord Krishna Bank) with a difference of 12.63 percentage points, M5 (Centurion Bank of Punjab and Lord Krishna Bank) with a difference of 7.80 percentage points, and M8 (between IDBI Bank and Untied Western Bank) with a difference of 14.08 percentage points. Overall, the bootstrap results reported in Table 5 suggest that our point estimates of gain/loss from the hypothetical mergers are quite reliable.

Arguably, evidence of potential cost savings based on the data from a single pre-merger year makes a rather weak case for merger because the year considered may be quite atypical due to macroeconomic shocks (like recession) affecting the entire banking sector. In order to address this concern, for each merger, we measured the potential gain using the data for multiple pre-merger years going back up to 10 years or as far back as possible within the constraints of data availability ${ }^{12}$. For mergers M1 and M3, the

\footnotetext{
${ }^{12}$ As already stated, in many cases the merged input-output bundle fell outside the free disposal convex hull of the data for a particular year and the corresponding DEA LP for cost minimization had no feasible solution.
} 
measured potential gain was negative (indicating a loss) for all years whenever there was a feasible solution. Similarly, mergers M2 and M12 showed positive gains in every pre-merger year. In case of the other mergers, we find gain in some years and loss in the others. Facing such flip-flop results in several cases, we decided to regression the measured potential gain in one year on the gain in the immediately preceding year. Below is the fitted model (with standard errors in parenthesis):

$$
\begin{gathered}
g_{t}=0.1879+0.6100 g_{t-1} ; \\
(0.826) \quad(0.091) ; \\
\mathrm{R}-\text { squared }=0.359 ; \text { Total observations }=83 .
\end{gathered}
$$

The p-values corresponding to the two coefficients are: 0.821 (intercept) and 0.000. The regression in (25) implies that if we obtained a $10 \%$ potential gain from a merger two years earlier, then we would find a gain of $6.2879 \%$ from a hypothetical merger in the year before the merger. In fact so long as the loss in any year is no greater than $0.308 \%$, positive gains could be predicted in the following year.

\section{Gains from Merger: Comparing Pre and Post Merger years}

Ideally one would like to find out whether there was a reduction in cost once the merger took place. The problem, of course, is that the acquired bank no longer operates as a separate unit after merger. As a result, there is no apparent benchmark for comparing the cost of the merged bank with the sum of the two standalone costs. We seek to overcome this problem by 'breaking up' the merged bank into two (or more if the number of banks merged was higher) separate banks each with its own input-output bundles. To create these counter-factual input-output bundles, we take any input or output of the merged bank and then allocate it to the constituent banks according to their shares in the aggregate quantity in the premerger year. Once these hypothetical bundles are created in the post-merger year, we measure the gain by the difference between the sum of the costs of the separate bundles and the cost of the aggregate bundle evaluated at the input prices paid by the acquiring bank. The findings for gains in the immediate post-merger year are presented in Table 6. It can be seen that out of the 11cases where all LP problems had feasible solutions, in 4 cases pre-and post-merger gains were both positive, in 1 case they were both negative, in 2 cases potential pre-merger gain was positive but post-merger gain was negative, and in 2 cases the opposite was true. It is clear, therefore, that potential gain or loss using pre-merger data is not a reliable predictor of what will happen subsequently. 
Pre- and Most Merger Cost Efficiency

In Table 7 we report the pre and post-merger cost efficiency of the merged bank. Like in Rhoades (1998), for the pre-merger year, we construct an aggregate measure of the cost efficiency of the merging banks and compare that with the cost efficiency of the acquiring bank in subsequent years after the merger. However, aggregation weights in Rhoades (1998) are based on the total assets of the merging entities, while we are weighing directly over the actual cost shares of the firms. The aggregate efficiency of the merging banks is created in the following way. Suppose that in year (t-1), banks A and B operate as separate business entities before the merger (that takes place in year $\mathrm{t}$ ). Further, the actual costs of these two banks in period (t-1) are $C_{t-1}^{0 A}$ and $C_{t-1}^{0 B}$ while their respective optimal costs are $C_{t-1}^{* A}$ and $C_{t-1}^{* B}$. Then, their aggregate cost efficiency is

$$
\gamma_{M}=\frac{C_{t-1}^{* A}+C_{t-1}^{* B}}{C_{t-1}^{0 A}+C_{t-1}^{0 B}}=\frac{C_{t-1}^{* A}}{C_{t-1}^{0 A}} \cdot \frac{C_{t-1}^{0 A}}{C_{t-1}^{0 A}+C_{t-1}^{0 B}}+\frac{C_{t-1}^{* B}}{C_{t-1}^{0 B}} \cdot \frac{C_{t-1}^{0 B}}{C_{t-1}^{0 A}+C_{t-1}^{0 B}}=\alpha_{A} \cdot \gamma_{t-1}^{A}+\alpha_{B} \cdot \gamma_{t-1}^{B}
$$

where $\gamma_{t-1}^{j}(j=A, B)$ is the cost efficiency of bank $\mathrm{j}$ in period (t-1) and $\alpha_{j}(j=A, B)$ is the share in their total cost in that period. The findings from Table 7 are best summarized by comparing the aggregated efficiency in the premerger year with the average cost efficiency of the acquiring bank over the initial 3 years following the merger reported in the last column of the table. We find sharp increase in cost efficiency after merger for M6 (from 0.77 to 0.93 ), M9 (from 0.61 to 1.0) and M13 (from 0.87 to 0.98 ). At the same time there were instances of sharp drop in cost efficiency for M8 (from 0.90 to 0.81 ) and more so for M10 (from 0.94 to 0.64). In 3 other cases there was moderate decline in cost efficiency (from 0.85 to 0.80 from M1, from 0.94 to 0.92 for M4, and from 0.90 to 0.86 for M12). In the remaining cases, there was not any noticeable change. Our findings on a potential for a gain from mergers M11, M12, and M13 and post-merger efficiency changes are in line with the results of Gourlay et al. (2016). ${ }^{13}$

\section{Potential Gain from Merger measured by Technical Efficiency}

Finally, we report the so called Merger Efficiency defined by BW showing the proportional reduction in the aggregated input bundle of the merging banks measured in the year before the merger. Their merger efficiency is measured by the radial input-oriented technical efficiency of the hypothetically merged unit operating as a single firm. A value greater than 1 implies that in order to produce the combined output bundle as a single firm, it would require an expansion of the combined input bundle. This implies negative input saving and, hence, a loss from the merger. Similarly, a value less than unity implies that

${ }^{13}$ M11, M12 and M13 are the only merger cases common between our paper and the study by Gourlay et al. (2016). 
the combined output could be produced by the merged unit with a radially scaled down input bundle and merger would yield positive gains. BW provide a multiplicative decomposition of the merger efficiency into there distinct components which they describe as technical efficiency, harmony effect, and scale or size effect. When the two input bundles are combined, the input-mix of the combined bundle corresponds to that of the average of the two bundles. When isoquants are convex, this leads to some input saving. Note that their harmony effect corresponds to our (trans-ray convexity of the cost function). Their scale effect reflects the nature of local returns to scale at the aggregated input-output bundle. This corresponds to (but is not strictly comparable with) our sub-additivity component, which is different from scale economies at the aggregated output bundle.

It would be interesting to compare the findings from their merger efficiency values reported in Table 8 with our potential gains (in cost) reported in Table 3. One thing needs to be mentioned here. Our potential gains/losses from merger are calculated from short run total cost curves where variable inputs are freely chosen given the output bundle and the level of fixed input. In case of the BW results, radial scaling factor has been applied to all of the variable inputs. In spite of this difference, the two results are in close agreement. In all cases where their merger efficiency exceeds unity (signifying a loss), we also find a potential loss. The only disagreement between the two is in the case of M11 where their merger efficiency would imply a gain but we do find a very small loss $(0.44 \%)$.

\section{$\underline{\text { Summary of Findings }}$}

The main findings of this study can be summarized as follows:

- Gains in terms of cost reduction are more prominent in case of voluntary mergers. Significant gains are not seen in forced mergers. This is not surprising given that the process of consolidation in the voluntary mergers is market driven, motivated by costs/profit considerations. Insofar as compulsory mergers are concerned, these are induced by RBI, mostly in the public interest.

- Convexity accounts for a small portion of the total gains from a merger. The convexity effect depends on two factors: heterogeneity in the output-mix of the merging banks and the curvature of the production possibility set. Small convexity effect suggests that the Indian banks are either not very specialized in terms of the products and services they offer or that the marginal rate of transformation between their outputs stays more or less constant, irrespective of the mix. ${ }^{14}$

\footnotetext{
${ }^{14}$ We calculated the Hamming index of Blancard et al. (2016) and the Euclidean distance to measure the difference between two given output bundles. The numbers can be provided on request. A simple Euclidean distance measure of difference in two output vectors indicates that product mix of the banks is quiet similar, being close to 0 in most cases. Slightly bigger indices are observed in the cases of banks in distant geographical markets like Centurion Bank of Punjab and Lord Krishna Bank (Euclidean distance of 0.2) and Bank of Baroda and Benares State Bank
} 
- The greater part of potential cost savings from a merger comes from the sub-additivity and capital expansion component. We find evidence of cost reduction due to sub-additivity even when the merged output bundle is in the region of diseconomies of scale, example M3 and M5. In 7 out of the 13 cases, we find positive sub-additivity effect and only 1 out of these 7 mergers reveals a potential overall loss from merging.

- When a very small bank is combined with a very large bank, the addition to the fixed cost of production is nominal, but saving in variable costs on account of transfer of assets to more productive management is often quite large. Thus, we find gains from capital expansion in such cases, for example, mergers M6, M7, M8 and M11. A merger between similar-sized banks or a large and a medium bank produce mixed results.

- Our bias corrected bootstrap estimates reveal that there is a $95 \%$ probability that the gains from mergers are of the same sign and magnitude as our potential estimates. This lends a great measure of credibility to the role of our analysis in explaining the cost effects of a merger. The results show more than $50 \%$ probability of a positive gain in 8 merger cases.

- Our results of a potential gain/loss from a merger are consistent with the more accepted BW approach. Unlike the radial approach of BW which does not take care of the input slacks, our model allows for non-proportional change in the variable inputs with exogenously given level of equity and is therefore more economically meaningful.

\section{Conclusion}

In this paper we offer a conceptual model for measuring potential gains in the form of cost savings from a merger of two or more firms within an industry and offer an additive decomposition of such gains to three distinct components that can be ascribed to (a) convexity of the technology, (b) sub-additivity of the ray short run total cost curve, and (c) a trade off between an increase in the fixed cost and a reduction in total variable costs. Appropriate linear programming problems are formulated to measure the total gain and the individual components using the nonparametric method of DEA. We use data from a number of recent bank mergers in India to empirically illustrate how our proposed analytical models can be applied to evaluate how much gain could have been realized if the merger between the banks involved had actually occurred in the year preceding the actual merger.

While our empirical finings do provide insights about cost savings due to merger, for practical policy decisions, many other factors need to be taken into consideration. An important consideration is to what

(Euclidean distance of 0.5). Accordingly, gains from convexity for such mergers are comparatively higher, implying that difference in mix maters. Despite not very diverse product-mix, about $50 \%$ of the gains from merger M9 comes due to convexity; this suggests that the production frontier facing banks is not flat throughout. 
extent the post-merger output of the merged bank will differ from the combined pre-merger output of the merging banks. If either the output-mix (i.e. the gradient of the ray in the output space) and/or the scale of output changes significantly over time, the conclusions drawn from the analysis of pre-merger data will become irrelevant. In that sense, our method is more applicable to mergers between units under a given decision making authority where the future outputs of constituent units as also their fixed inputs are decided at the corporate planning level and are far more predictable. 


\section{References}

Al-Sharkas, A., Hassan, M., Lawrence, S., 2008. The impact of mergers and acquisitions on the efficiency of the US banking industry: further evidence. Journal of Business Finance Accounting., 35(1\&2), 50-70.

Altunbaş, Y., Ibanez, D.M., 2008. Mergers and Acquisitions and Bank Performance in Europe: The Role of Strategic Similarities. Journal of Economics and Business, 60.3 (2008): 204-22. Web.

Baumol, W., 1977. On the Proper Cost Tests for Natural Monopoly in a Multiproduct Industry. The American Economic Review, 67(5), 809-822.

Baumol, W., Fischer, D., 1978. Cost-Minimizing Number of Firms and Determination of Industry Structure. The Quarterly Journal of Economics, 92(3), 439-467.

Baumol, W., Panzar, J., Willig, R., 1982. Contestable Markets and the Theory of Industry Structure, Harcourt Brace Jovanovich, Inc., New York.

Berger, A. N., Humphrey, D. B., 1992. Measurement and efficiency issues in commercial banking. In Output measurement in the service sectors (pp. 245-300). University of Chicago Press.

Berger, A. N., Humphrey, D. B., 1997. Efficiency of financial institutions: International survey and directions for future research. European Journal of Operational Research, 98(2), 175-212.

Berger, A.N., Mester. L., 2003. Explaining the dramatic changes in performance of US banks: Technological change, deregulation, and dynamic changes in competition. Journal of Financial Intermediation, 12(1), 57-95.

Blancard, S., Boussemart, J.P., Chavas, J.P., Leleu. H., 2016. Potential gains from specialization and diversification further to the reorganization of activities. Omega, 63, 60-68.

Bogetoft, P., Wang, D., 2005. Estimating the Potential Gains from Mergers. Journal of Productivity Analysis, 23(2), 145-171.

Campa, J.M., Hernando, I., 2006. M\&As Performance in the European Financial Industry. Journal of Banking and Finance, 30.12: 3367.

Chavas, J.P., Kim, K., 2010. Economies of diversification: A generalization and decomposition of economies of scope. International Journal of Production Economics, 126(2), 229-235.

Cornett, M.M., Hovakimian, G., Palia, D., Tehranian, H., 2003. The Impact of the Managershareholder Conflict on Acquiring Bank Returns. Journal of Banking and Finance, 27.1 (2003): 103-31.

De Guevara, J.F., Maudos, J., 2007. Explanatory Factors of Market Power in the Banking System. Manchester School, 75.3: 275-96. 
De Guevara, J.F., Maudos, J., Pérez, F., 2005. Journal of Financial Services Research, 27: 109. https://doi.org/10.1007/s10693-005-6665-z

DeLong, G.L., 2001. Stockholder Gains from Focusing versus Diversifying Bank Mergers. Journal of Financial Economics, 59.2: 221-52. Web.

DeLong, G.L., DeYoung, R., 2007. Learning by Observing: Information Spillovers in the Execution and Valuation of Commercial Bank M\&As. The Journal of Finance 62.1 (2007): 181216.

DeYoung, R., Evanoff, D., Molyneux, D., 2009. Mergers and Acquisitions of Financial Institutions: A Review of the Post-2000 Literature. Journal of Financial Services Research, 36(2), 87-110.

Eder, A., 2018. Measuring and decomposing economies of diversification: An application to biogas-fuelled cogeneration plants in Austria. International Journal of Production Economics, 204, 421-432.

Emmons, W.R., Gilbert, R.A., Yeager, T.J., 2004. Reducing the Risk at Small Community Banks: Is It Size or Geographic Diversification That Matters? Journal of Financial Services Research 25.2 (2004): 259-81. Web.

Fadzlan, S., 2004. The Eficiency Effects of Bank Mergers and Acquisitions in a Developing Economy: Evidence from Malaysia. International Journal of Applied Econometrics and Quantitative Studies, Euro-American Association of Economic Development, vol. 1(4), pages 5374.

Fried, H.O., Lovell, C.A.K., Yaisawarng. S., 1999. The impact of mergers on credit union service provision. Journal of Banking and Finance, 23(2), 367-386.

Gattoufi, S., Amin, G., Emrouznejad, A., 2014. A new inverse DEA method for merging banks. IMA Journal of Management Mathematics, 25(1), 73-87.

Gourlay, A., Ravishankar, G., Weyman-Jones, T., 2006. Non-Parametric Analysis of Efficiency Gains from Bank Mergers in India. IDEAS Working Paper Series from RePEc.

Hosono, K., Sakai, K., Tsuru, K., 2006. Consolidation of Cooperative Banks (Shinkin) in Japan: Motives and Consequences. IDEAS Working Paper Series from RePEc.

Houston, J.F., Ryngaert, M.D., 1994. The overall gains from large bank mergers. Journal of Banking and Finance, 18:1155-1176

Houston, J.F., James, C.M., Ryngaert, M.D., 2001. Where Do Merger Gains Come From? Bank Mergers from the Perspective of Insiders and Outsiders. Journal of Financial Economics 60.2 (2001): 285-331.

Humphrey, D.B., Vale, B., 2004. Scale Economies, Bank Mergers, and Electronic Payments: A Spline Function Approach. Journal of Banking and Finance, 28.7: 1671-696. Web. 
Kaur, P., Kaur, G., 2010. Impact of Mergers on the Cost Efficiency of Indian Commercial Bank. Eurasian Journal of Business and Economics, 3(5), 27-50.

Kiesel, F., Ries, J.M., Tielmann, A., 2017. The impact of mergers and acquisitions on shareholders' wealth in the logistics service industry. International Journal of Production Economics, 193(C), 781-797.

Knapp, M., Gart, A., Becher, D.A., 2005. Post-Merger Performance of Bank Holding Companies, 1987-1998. The Financial Review, 40.4 (2005): 549-74.

Kollapuri, M., 2017. Bank Consolidation and Efficiency: an Empirical Study from India. Centre for International Trade and Development, Jawaharlal Nehru University, New Delhi Discussion Papers, 17-03.https://ideas.repec.org/p/ind/citdwp/17-03.html

Kumar, S., 2013. Impact of Bank Mergers on the Efficiency of Banks: A study of merger of Bharat Overseas Bank with Indian Overseas Bank. International Journal of Academic Research in Business and Social Sciences, 3 (12), 221 - 242.

Kumar, S., Gulati, R., 2014. Deregulation and Efficiency of Indian Banks. 10.1007/978-81-3221545-5.

Lin, H.T., 2010. An efficiency-driven approach for setting revenue target. Decis. Support Syst., 49(2010), 311-317.

Lin, L., Kuo, H. C., Lin, I. L., 2008. Merger and optimal number of firms: An integrated simulation approach. Applied Economics, 40(18), 2413-2421.

Lien-Wen, L., 2011. The Impact of Bank Mergers on the Cost Efficiency of Taiwanese and Japanese Banking. Journal of Accounting, Finance and Management Strategy, 6(1), 59-82.

Lozano, S., 2013. Using DEA to find the best partner for a horizontal cooperation. Computers and Industrial Engineering, 66(2), 286-292.

Mattsson, P., Tidanå, C., 2019. Potential efficiency effects of merging the Swedish district courts. Socio-Economic Planning Sciences, 67, 58-68.

Mondal, G., Pal, M., Ray, S., 2017. Influence of Merger on Performance of Indian Banks: A Case Study. Journal of Poverty, Investment and Development, Vol., 32.

Mylonidis, N., Kelnikola, I., 2005. Merging activity in the Greek Banking System: A Financial Accounting Perspective. South-Eastern Europe Journal of Economics, Association of Economic Universities of South and Eastern Europe and the Black Sea Region, vol. 3(1), pages 121-144.

Naga, S., Tabassum, S., 2013. Financial Performance Analysis in Banking Sector - A Pre and Post Merger Perspective. Advances in Management, 6(10), 55-61.

Patel, R., Shah, D., 2016. Mergers and Acquisitions: A Pre-post Risk - Return Analysis for the Indian Banking Sector. Journal of Applied Finance and Banking, 6(3), 99-113. 
Peristiani, S., 1997. Do Mergers Improve the X-Efficiency and Scale Efficiency of U.S. Banks? Evidence from the 1980s. Journal of Money, Credit and Banking, 29(3), 326-337.

Pilloff, S.J., 1996. Performance Changes and Shareholder Wealth Creation Associated with Mergers of Publicly Traded Banking Institutions. Journal of Money, Credit and Banking, 28.3: 294-310.

Ray, S., 2015. Nonparametric measures of scale economies and capacity utilization: An application to U.S. manufacturing. European Journal of Operational Research, 245(2), 602-611.

Ray, S., Das, A., 2010. Distribution of cost and profit efficiency: Evidence from Indian banking. European Journal of Operational Research, 201(1), 297-307.

Ray, S., Hu, C., 1997. On the Technically Efficient Organization of an Industry: A Study of U.S. Airlines. Journal of Productivity Analysis, 8(1), 5-18.

Ray, S., Walden, J., Chen, L., 2018. Economic Measures of Capacity Utilization: A Nonparametric Cost Function Analysis. Working papers 2018-02, University of Connecticut, Department of Economics.

Resti, A. Siciliano, G., 2001. Do Bank Acquisitions Increase Shareholders' Wealth? A Comparison between Market-Based and Accounting-Based Performance Indicators for Some Italian Banks. Available at SSRN: https://ssrn.com/abstract=223523 or http://dx.doi.org/10.2139/ssrn.223523

Rhoades, S.A., 1998. The Efficiency Effects of Bank Mergers: An Overview of Case Studies of Nine Mergers. Journal of Banking and Finance, 22.3: 273-91. Web.

Sealey, C., Lindley, J., 1977. Inputs, outputs, and a theory of production and cost at depository financial institutions. Journal of Finance, 32(4), 1251-1266.

Sensarma, R., Jayadev, M., 2010. Efficiency, scale economies and valuation effects: evidence from bank mergers in India. International Journal of Financial Services Management, Inderscience Enterprises Ltd, vol. 4(4), pages 311-337.

Shi, X., Li, Y., Emrouznejad, A., Xie, J., Liang, L., 2017. Estimation of potential gains from bank mergers: A novel two-stage cost efficiency DEA model. Journal of Operational Research Society, 68(9), 1045-1055.

Simar, L., Wilson, P.W., 1998. Sensitivity Analysis of Efficiency Scores: How to Bootstrap in Nonparametric Frontier Models. Management Science, 44(1), 49-61.

Singh, P., 2009. Mergers in Indian Banking: Impact Study Using DEA Analysis. South Asian Journal of Management, 16(2), 7-27.

Sufian, F., Majid, A., Zulkhibri, M., Razali, H., 2008. Efficiency and bank merger in Singapore: a joint estimation of non-parametric, parametric and financial ratios analysis. MPRA paper no 12129. Available via DIALOG. http://mpra.ub.uni-muenchen.de/12129/. 
Valverde, S.C., Humphrey, D.B., 2004. Predicted and Actual Costs from Individual Bank Mergers. Journal of Economics and Business, 56.2: 137-57. Web.

Yuan, Z., Chen, F.Y., Yan, X., Yu, Y., 2020. Operational implications of yield uncertainty in mergers and acquisitions. International Journal of Production Economics, 219, 248-258. 


\section{List of Figures}

Figure 1. Trans-Ray Convexity of short-run cost curves

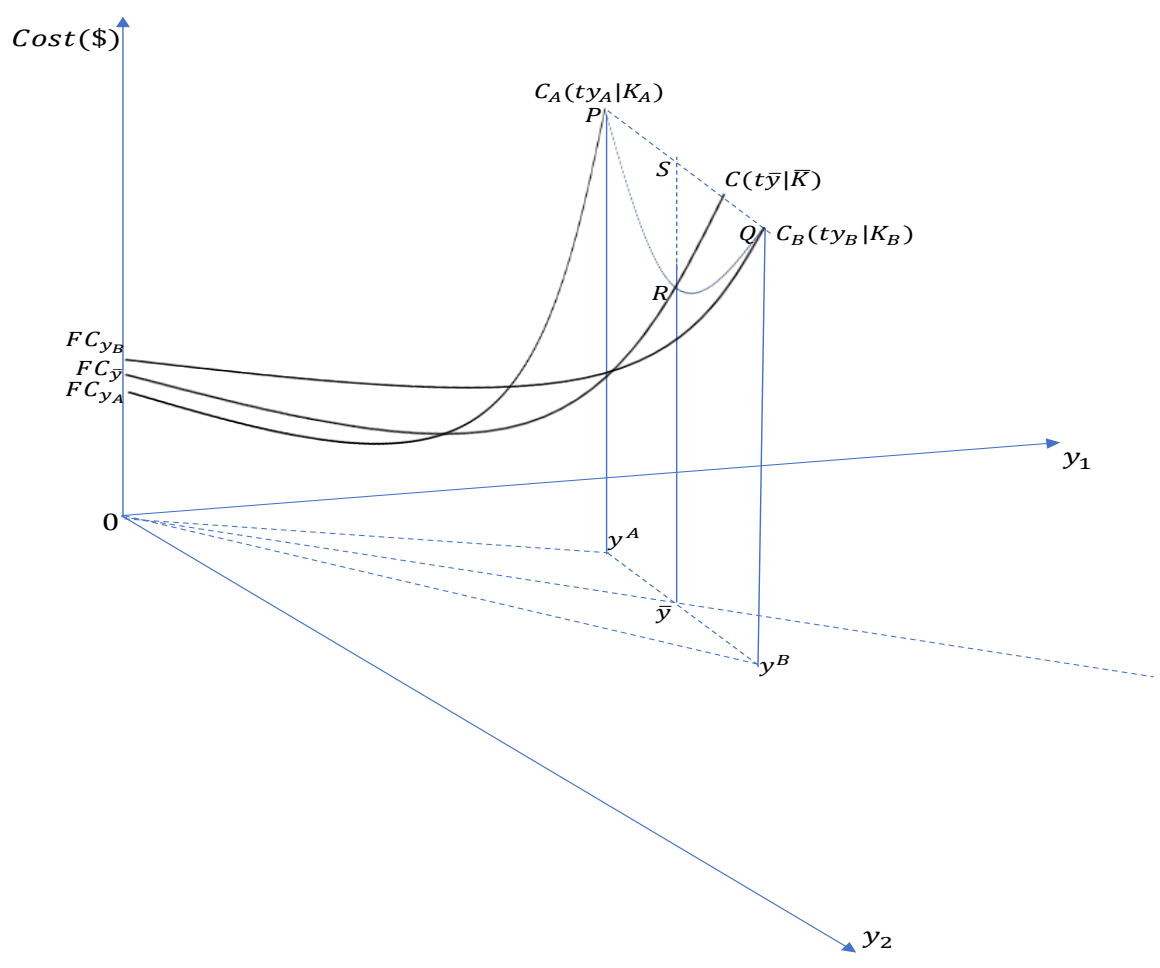

Figure 2. Sub-additivity of the short-run Ray cost curve

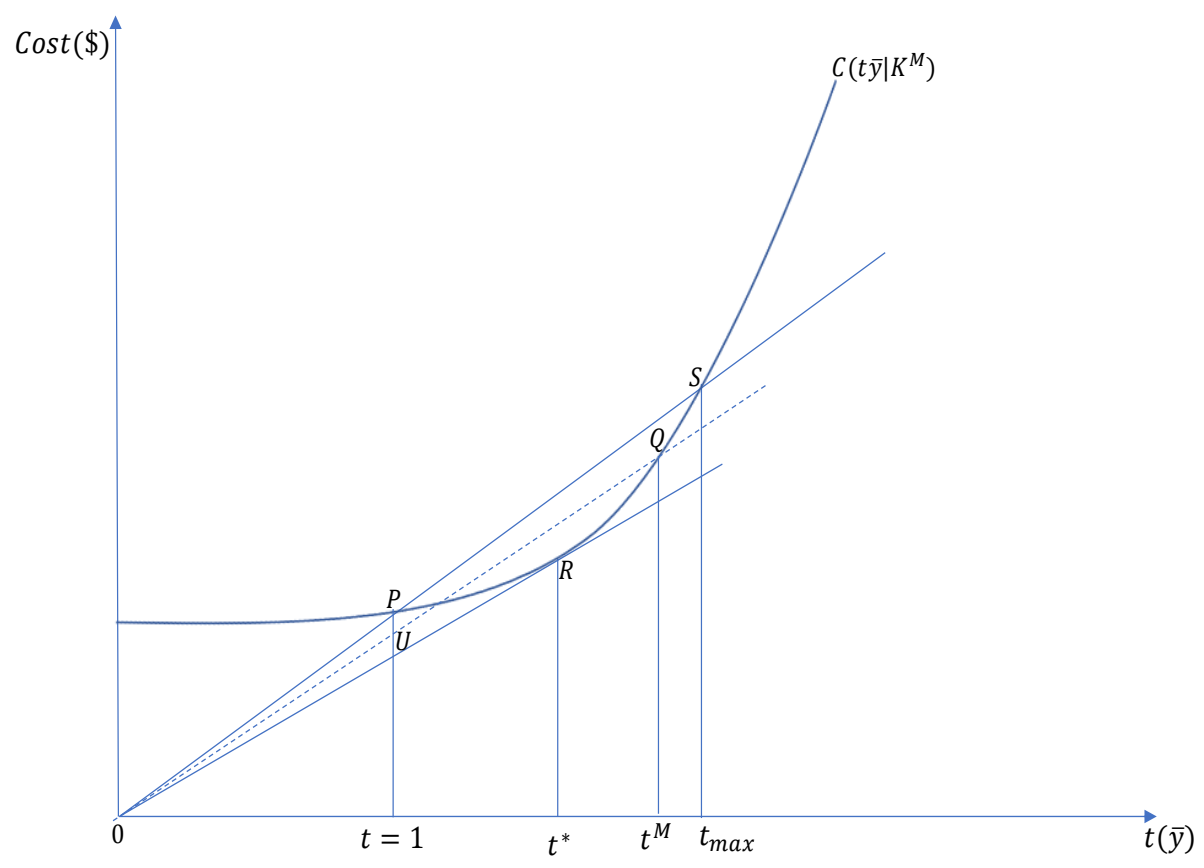


Figure 3. Capital Expansion and Tradeoff between Fixed and Variable Costs

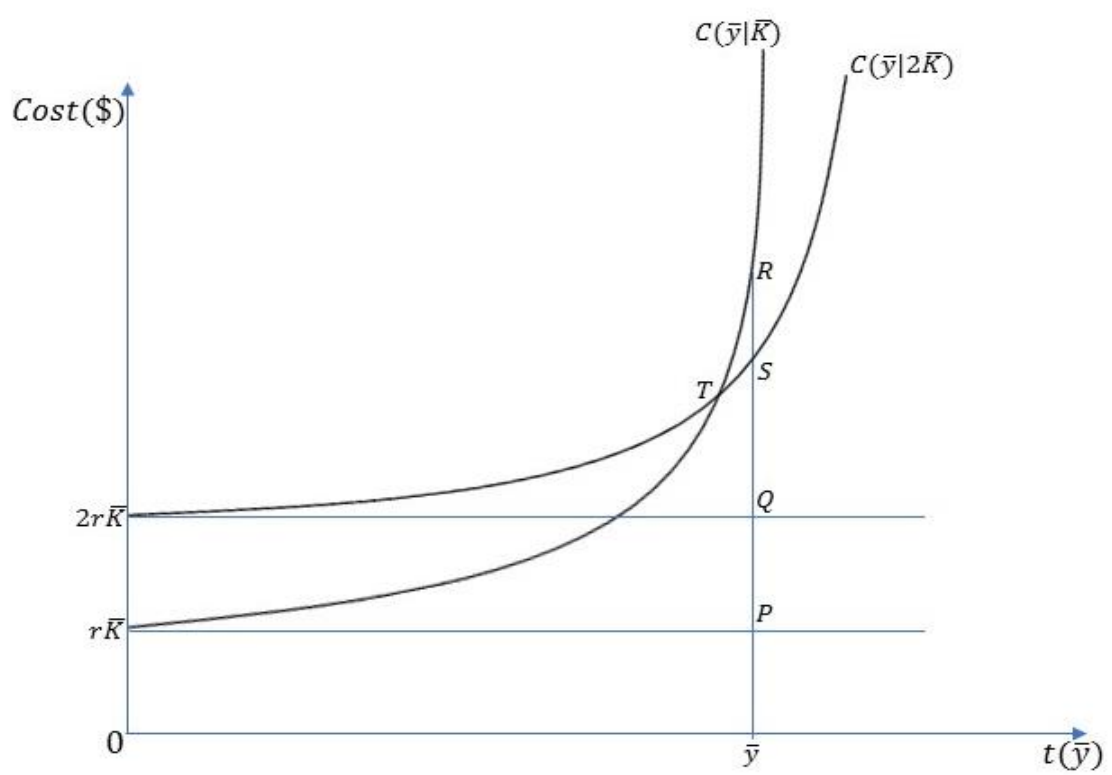




\section{List of Tables}

Table 1: List of selected bank mergers in India between 2000-2019

\begin{tabular}{|c|c|c|c|c|c|}
\hline $\begin{array}{l}\text { Merger } \\
\text { Number }\end{array}$ & $\begin{array}{l}\text { Type of } \\
\text { merger }\end{array}$ & Acquiring Bank & Acquired Banks & $\begin{array}{l}\text { Year } \\
\text { of } \\
\text { merger }\end{array}$ & $\begin{array}{c}\text { No. of } \\
\text { Merging } \\
\text { Banks }\end{array}$ \\
\hline M1 & Forced & Bank of Baroda $(\mathrm{P})$ & $\begin{array}{l}\text { Dena Bank }(\mathrm{P}) \\
\text { Vijaya Bank }(\mathrm{P})\end{array}$ & 2019 & 3 \\
\hline M2 & Forced & Kotak Mahindra Bank (Pvt) & ING Vysya Bank (Pvt) & 2016 & 2 \\
\hline M3 & Forced & ICICI Bank (Pvt) & Bank of Rajasthan (Pvt) & 2010 & 2 \\
\hline $\mathrm{M} 4^{1}$ & Voluntary & $\begin{array}{l}\text { HDFC Bank (Pvt) } \\
\text { Centurion Bank of Punjab }\end{array}$ & $\begin{array}{l}\text { Centurion Bank of Punjab (Pvt) } \\
\text { Lord Krishna Bank (Pvt) }\end{array}$ & 2008 & 3 \\
\hline $\mathrm{M}^{1}$ & Voluntary & $(\mathrm{Pvt})$ & Lord Krishna Bank (Pvt) & 2007 & 2 \\
\hline M6 & Forced & Indian Overseas Bank $(\mathrm{P})$ & Bharat Overseas Bank (Pvt) & 2007 & 2 \\
\hline M7 & Forced & IDBI Bank (P) & United Western Bank Ltd. (Pvt) & 2006 & 2 \\
\hline M8 & Forced & Federal Bank (Pvt) & Ganesh Bank of Kurundwad (Pvt) & 2006 & 2 \\
\hline M9 & Voluntary & Centurion Bank (Pvt) & Bank of Punjab (Pvt) & 2005 & 2 \\
\hline M10 & Forced & $\begin{array}{l}\text { Oriental Bank of Commerce } \\
\text { (P) }\end{array}$ & Global Trust Bank (Pvt) & 2004 & 2 \\
\hline M11 & Forced & Punjab National Bank (P) & Nedungadi Bank (Pvt) & 2003 & 2 \\
\hline M12 & Forced & Bank of Baroda (P) & Benares State Bank (Pvt) & 2002 & 2 \\
\hline M13 & Voluntary & ICICI Bank (P) & Bank of Madura (Pvt) & 2001 & 2 \\
\hline
\end{tabular}

${ }^{l}$ M4 involved the merger of only two banks: HDFC bank and Centurion Bank of Punjab. But, Centurion Bank of Punjab acquired Lord Krishna Bank in 2007. For analyzing the merger of HDFC bank and Centurion bank, we look at the last year of available data for the two merging entities. However, in 2007 we have data on all three banks HDFC, Centurion Bank of Punjab and Lord Krishna Bank, while in 2008 there is data only for HDFC Bank. Therefore, we analyze $M 4$ as the merger of 3 banks.

${ }_{2}^{2}(P)$ stands for Public sector banks and (Pvt) implies Private banks 
Table 2: Summary statistics of input and output variables

\begin{tabular}{|c|c|c|c|c|c|c|c|c|}
\hline \multirow{2}{*}{ Years } & \multirow{2}{*}{ Statistic } & \multirow{2}{*}{$\begin{array}{l}\text { Employee } \\
\text { (No. of Employees) }\end{array}$} & \multirow[t]{2}{*}{ Deposits } & \multirow[t]{2}{*}{ Fixed_Assets } & \multirow[t]{2}{*}{ Equity } & \multirow[t]{2}{*}{ Investments } & \multirow{2}{*}{\multicolumn{2}{|c|}{$\begin{array}{c}\text { Good Loans Other Income } \\
\text { Rs Million (2004-05 prices) }\end{array}$}} \\
\hline & & & & & & & & \\
\hline \multirow{5}{*}{2000} & Count & 59 & 59 & 59 & 59 & 59 & 59 & 59 \\
\hline & Average & 15,931 & 111,891 & 1,732 & 7,148 & 50,517 & 49,789 & 1,805 \\
\hline & Minimum & 118 & 1,075 & 30 & 51 & 265 & 548 & 7 \\
\hline & Maximum & 233,433 & $1,526,861$ & 19,220 & 94,234 & 712,759 & 712,254 & 27,689 \\
\hline & Standard Deviation & 32,734 & 212,013 & 2,823 & 13,229 & 97,039 & 98,214 & 3,712 \\
\hline \multirow{5}{*}{2010} & Count & 49 & 49 & 49 & 49 & 49 & 49 & 49 \\
\hline & Average & 18,820 & $1,205,181$ & 11,934 & 96,361 & 419,018 & 880,179 & 18,503 \\
\hline & Minimum & 71 & 6,429 & 117 & 1,684 & 4,176 & 2,683 & 76 \\
\hline & Maximum & 200,299 & $10,517,840$ & 57,721 & 862,616 & $3,868,870$ & $8,123,272$ & 195,783 \\
\hline & Standard Deviation & 29,866 & $1,647,731$ & 13,812 & 156,220 & 605,407 & $12,65,809$ & 31,573 \\
\hline \multirow{5}{*}{2018} & Count & 42 & 42 & 42 & 42 & 42 & 42 & 42 \\
\hline & Average & 30,166 & $4,811,173$ & 58,170 & 440,562 & $1,622,936$ & $3,345,720$ & 77,472 \\
\hline & Minimum & 844 & 131,389 & 606 & 11,139 & 30,550 & 59,597 & 636 \\
\hline & Maximum & 264,041 & $48,498,429$ & 716,672 & $3,926,845$ & $19,013,179$ & $32,687,047$ & 799,257 \\
\hline & Standard Deviation & 43,013 & $7,741,137$ & 112,232 & 695,181 & $2,950,760$ & $5,340,591$ & 133,785 \\
\hline
\end{tabular}

${ }^{1}$ Out of 59 observations in 2000, 27 were Public Sector Banks and 32 Private Banks. The number of public and private sector banks in 2010 were 27 and 22 respectively; corresponding numbers in 2018 were 21 and 21. 
Table 3: Gains from merger and its decomposition

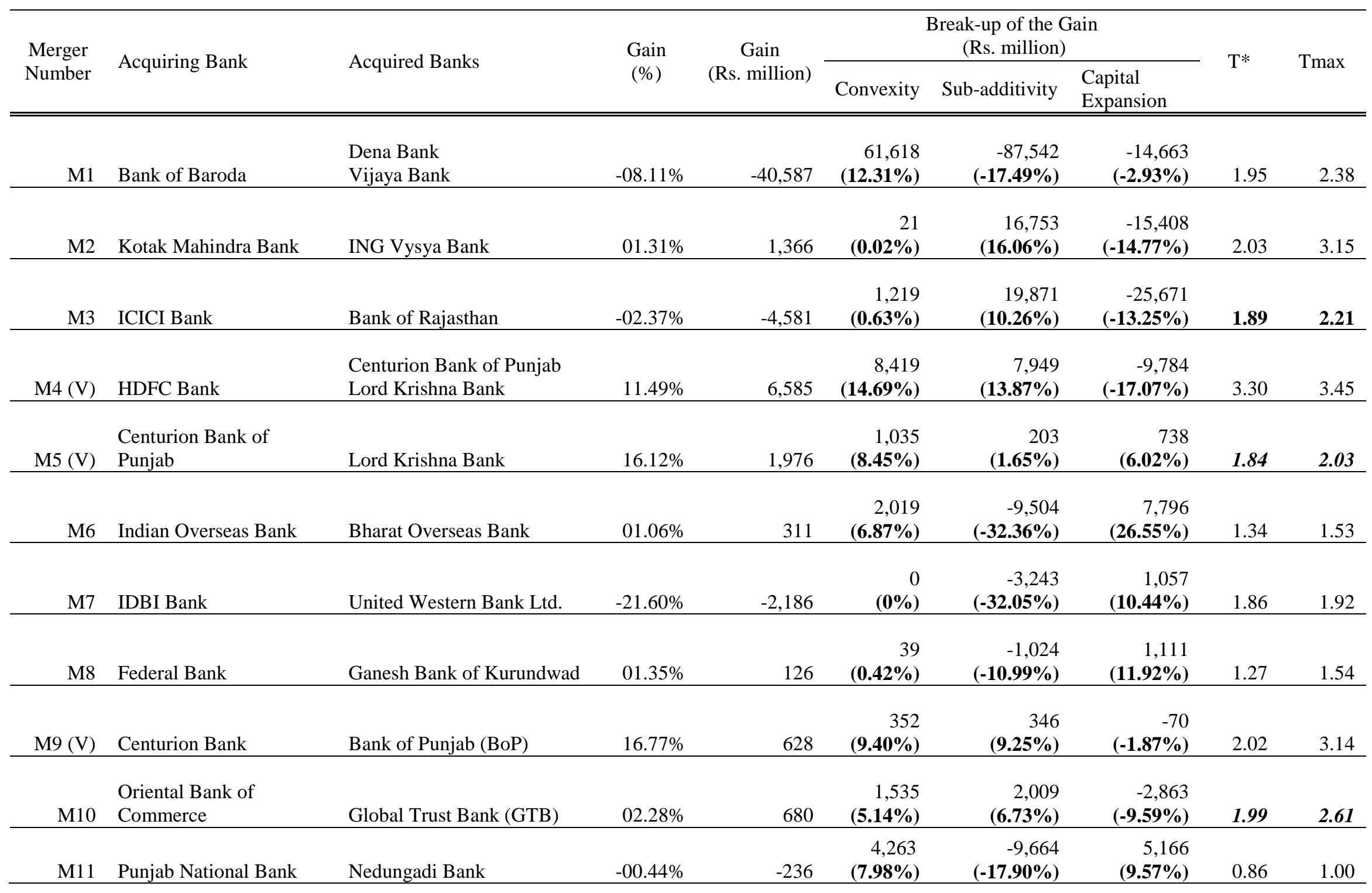




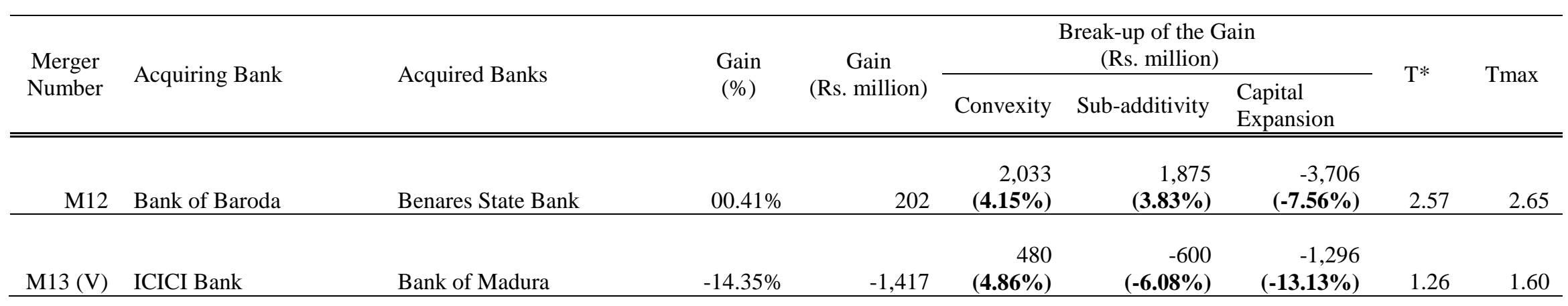

${ }^{I}$ Negative gain implies a loss.

${ }^{2}$ Percentages in parenthesis represent the share of each component in the sum of standalone costs of individual banks. Numbers in bold in the $T^{*}$ and Tmax columns represent merger cases where $T^{*}<$ number of merging banks $<$ Tmax.

$3(V)$ in column 1, implies voluntary merger.

Table 4: Measurement of Gain from Merger 9

\begin{tabular}{lccccc}
\hline Bank & Investment & Loans & Other Income & Equity & Optimal Cost \\
\hline Centurion Bank & 14,796 & 21,393 & 722 & 5,900 & 1,684 \\
Bank of Punjab & 14,027 & 23,048 & 691 & 2,412 & 2,059 \\
Total & $\mathbf{2 8 , 8 2 3}$ & $\mathbf{4 4 , 4 4 2}$ & $\mathbf{1 , 4 1 3}$ & $\mathbf{8 , 3 1 2}$ & $\mathbf{3 , 7 4 3}$ \\
Average & 14,412 & 22,221 & 706 & 4,156 & 1,696 \\
Merged & & & & & $\mathbf{3 , 1 1 5}$ \\
\hline
\end{tabular}

${ }^{1}$ All numbers are ₹ millions 
Table 5: Results from the Bootstrapping Analysis

\begin{tabular}{|c|c|c|c|c|c|c|c|}
\hline \multirow{2}{*}{$\begin{array}{l}\text { Merger } \\
\text { Number }\end{array}$} & \multirow{2}{*}{ Acquiring Bank } & \multirow{2}{*}{ Acquired Banks } & \multirow{2}{*}{$\begin{array}{l}\text { Potential } \\
\text { Gain }(\%)\end{array}$} & \multicolumn{3}{|c|}{ Bootstrap Gains (Bias Corrected) } & \multirow{2}{*}{$\begin{array}{c}\text { Cumulative } \\
\text { Probability } \\
\text { Of a Gain }\end{array}$} \\
\hline & & & & $5 \%$ & $50 \%$ & $95 \%$ & \\
\hline M1 & ${ }^{* 1}$ Bank of Baroda & $\begin{array}{l}\text { Dena Bank } \\
\text { Vijaya Bank }\end{array}$ & $-08.11 \%$ & $-10.68 \%$ & $-08.52 \%$ & $-06.52 \%$ & 0.00 \\
\hline M2 & Kotak Mahindra Bank & ING Vysya Bank & $01.31 \%$ & $-04.91 \%$ & $00.06 \%$ & $03.83 \%$ & 0.51 \\
\hline M3 & ${ }^{* 2}$ ICICI Bank & Bank of Rajasthan & $-02.37 \%$ & $-05.54 \%$ & $02.47 \%$ & $03.59 \%$ & 0.72 \\
\hline M4 (V) & ${ }^{* 3}$ HDFC Bank & $\begin{array}{l}\text { Centurion Bank of Punjab } \\
\text { Lord Krishna Bank }\end{array}$ & $11.49 \%$ & $-00.66 \%$ & $24.12 \%$ & $26.51 \%$ & 1.00 \\
\hline M5 (V) & Centurion Bank of Punjab & Lord Krishna Bank & $16.12 \%$ & $20.58 \%$ & $23.92 \%$ & $29.98 \%$ & 0.94 \\
\hline M6 & Indian Overseas Bank & Bharat Overseas Bank & $01.06 \%$ & $00.53 \%$ & $01.54 \%$ & $02.81 \%$ & 0.99 \\
\hline M7 & IDBI Bank & United Western Bank Ltd. & $-21.60 \%$ & $-28.26 \%$ & $-07.52 \%$ & $-02.88 \%$ & 0.00 \\
\hline M8 & Federal Bank & Ganesh Bank of Kurundwad & $01.35 \%$ & $00.50 \%$ & $00.93 \%$ & $01.92 \%$ & 1.00 \\
\hline M9 (V) & Centurion Bank & Bank of Punjab & $16.77 \%$ & $13.52 \%$ & $18.47 \%$ & $23.09 \%$ & 1.00 \\
\hline M10 & Oriental Bank of Commerce & Global Trust Bank & $02.28 \%$ & $-04.29 \%$ & $-02.42 \%$ & $-01.90 \%$ & 0.00 \\
\hline M11 & ${ }^{* 4}$ Punjab National & Nedungadi Bank & $-00.44 \%$ & $-02.21 \%$ & $-00.43 \%$ & $00.41 \%$ & 0.28 \\
\hline M12 & Bank of Baroda & Benares State Bank & $00.41 \%$ & $-00.34 \%$ & $00.34 \%$ & $00.84 \%$ & 0.88 \\
\hline M13 (V) & ICICI Bank & Bank of Madura & $-14.35 \%$ & $-19.91 \%$ & $-12.99 \%$ & $-09.35 \%$ & 0.00 \\
\hline
\end{tabular}

$1 *$ The 5-, 50- and 95-percentiles of the distribution of gains from merger are computed only from the bootstrap runs that did not generate infeasible solution for the merged bank. The number of infeasibilities for mergers 1, 2, 3 and 4 were 642, 81, 275 and 192 respectively.

${ }^{2}(V)$ indicates voluntary mergers 
Table 6: Results from post-merger analysis of gains

\begin{tabular}{|c|c|c|c|c|}
\hline $\begin{array}{l}\text { Merger } \\
\text { Number } \\
\end{array}$ & Acquiring Bank & Acquired Banks & $\begin{array}{l}\text { Potential } \\
\text { Gain(\%) }\end{array}$ & $\begin{array}{l}\text { Post Merger Gain } \\
\qquad(\%)\end{array}$ \\
\hline M1 & Bank of Baroda & $\begin{array}{l}\text { Dena Bank } \\
\text { Vijaya Bank }\end{array}$ & $-08.11 \%$ & NA \\
\hline M2 & Kotak Mahindra Bank & ING Vysya Bank & $01.31 \%$ & $-09.50 \%$ \\
\hline M3 & ICICI Bank & Bank of Rajasthan & $-02.37 \%$ & $00.00 \%$ \\
\hline M4 (V) & HDFC Bank & $\begin{array}{l}\text { Centurion Bank of Punjab } \\
\text { Lord Krishna Bank }\end{array}$ & $11.49 \%$ & $10.31 \%$ \\
\hline M5 (V) & Centurion Bank of Punjab & Lord Krishna Bank & $16.12 \%$ & NA \\
\hline M6 & Indian Overseas Bank & Bharat Overseas Bank & $01.06 \%$ & $00.47 \%$ \\
\hline M7 & IDBI Bank & United Western Bank Ltd. & $-21.60 \%$ & $00.00 \%$ \\
\hline M8 & Federal Bank & Ganesh Bank of Kurundwad & $01.35 \%$ & $01.77 \%$ \\
\hline M9 (V) & Centurion Bank & Bank of Punjab & $16.77 \%$ & $-03.18 \%$ \\
\hline M10 & Oriental Bank of Commerce & Global Trust Bank & $02.28 \%$ & $02.40 \%$ \\
\hline M11 & Punjab National & Nedungadi Bank & $-00.44 \%$ & $00.86 \%$ \\
\hline M12 & Bank of Baroda & Benares State Bank & $00.41 \%$ & $00.72 \%$ \\
\hline $\mathrm{M} 13(\mathrm{~V})$ & ICICI Bank & Bank of Madura & $-14.35 \%$ & $-08.24 \%$ \\
\hline
\end{tabular}


Table 7: Pre- and post-merger analysis of cost efficiency

\begin{tabular}{l|cccc|cccc}
\hline $\begin{array}{c}\text { Merger } \\
\text { Number }\end{array}$ & $\begin{array}{c}\text { Acquiring } \\
\text { Bank }\end{array}$ & $\begin{array}{c}\text { Acquired } \\
\text { Bank 1 }\end{array}$ & $\begin{array}{c}\text { Acquired } \\
\text { Bank 2 }\end{array}$ & $\begin{array}{c}\text { Merged } \\
\text { Bank }\end{array}$ & \multicolumn{3}{c}{ Post Merger Years } & \multicolumn{2}{c}{$\begin{array}{c}\text { Post-Merger } \\
\text { Average }\end{array}$} \\
\hline \hline M2 & 0.82 & 0.90 & & 0.85 & 0.78 & 0.84 & 0.77 & 0.80 \\
M3 & 1.00 & 0.90 & & 0.99 & 1.00 & 1.00 & 1.00 & 1.00 \\
M4 (V) & 0.93 & 1.00 & 0.93 & 0.94 & 1.00 & 0.92 & 0.85 & 0.92 \\
M5 (V) & 1.00 & 1.00 & & 1.00 & NA & NA & NA & NA \\
M6 & 0.77 & 0.79 & & 0.77 & 0.92 & 1.00 & 0.88 & 0.93 \\
M7 & 1.00 & 1.00 & 1.00 & 1.00 & 1.00 & 1.00 & 1.00 \\
M8 & 0.90 & 1.00 & 0.90 & 0.85 & 0.62 & 0.86 & 0.78 \\
M9 (V) & 0.61 & 0.61 & 0.61 & 1.00 & 1.00 & NA & 1.00 \\
M10 & 1.00 & 0.67 & 0.94 & 0.59 & 0.49 & 0.84 & 0.64 \\
M11 & 0.87 & 1.00 & 0.87 & 0.90 & 1.00 & 0.74 & 0.88 \\
M12 & 0.90 & 0.88 & 0.90 & 0.86 & 0.84 & 0.88 & 0.86 \\
M13 (V) & 0.90 & 0.82 & 0.87 & 0.95 & 1.00 & 1.00 & 0.98 \\
& & & & & & & \\
\hline
\end{tabular}

${ }^{I}(V)$ indicates voluntary mergers.

${ }^{2}$ For M5, the acquirer bank was acquired by another bank in the following year so post-merger efficiencies are not available (NA) for this merger.

Table 8: Results from radial input-oriented efficiency analysis based on Bogetoft and Wang (2005) approach.

\begin{tabular}{lrrrr}
\hline $\begin{array}{c}\text { Merger } \\
\text { Number }\end{array}$ & $\begin{array}{c}\text { Merger } \\
\text { Efficiency }\end{array}$ & $\begin{array}{c}\text { Technical } \\
\text { Efficiency }\end{array}$ & $\begin{array}{c}\text { Harmony } \\
\text { Effect }\end{array}$ & $\begin{array}{c}\text { Scale } \\
\text { Effect }\end{array}$ \\
\hline \hline M1 & $\mathbf{1 . 2 4 9}$ & 0.922 & 0.874 & 1.551 \\
M2 & $\mathbf{0 . 8 5 5}$ & 0.866 & 0.990 & 0.996 \\
M3 & $\mathbf{1 . 0 6 0}$ & 1.000 & 1.000 & 1.060 \\
M4 & $\mathbf{0 . 9 6 7}$ & 1.000 & 0.883 & 1.095 \\
M5 & $\mathbf{0 . 9 2 0}$ & 1.000 & 0.978 & 0.941 \\
M6 & $\mathbf{0 . 8 3 4}$ & 0.847 & 0.932 & 1.056 \\
M7 & $\mathbf{1 . 2 7 9}$ & 1.000 & 1.000 & 1.279 \\
M8 & $\mathbf{0 . 9 0 1}$ & 0.913 & 1.000 & 0.987 \\
M9 & $\mathbf{0 . 5 2 5}$ & 0.679 & 0.818 & 0.946 \\
M10 & $\mathbf{0 . 9 5 9}$ & 1.000 & 0.885 & 1.083 \\
M11 & $\mathbf{0 . 9 4 5}$ & 0.953 & 0.959 & 1.034 \\
M12 & $\mathbf{0 . 9 0 8}$ & 0.918 & 0.956 & 1.035 \\
M13 & $\mathbf{1 . 7 9 1}$ & 0.945 & 0.900 & 2.107 \\
\hline
\end{tabular}

